\title{
Safety Assessment and a Parametric Study of Forward Collision-Avoidance Assist Based on Real-World Crash Simulations
}

\author{
MohammadReza Seyedi ${ }^{D},{ }^{1}$ MohammadReza Koloushani ${ }^{1},{ }^{1}$ Sungmoon Jung ${ }^{1 D},{ }^{1}$ \\ and Arda Vanli $\left.{ }^{2}\right)^{2}$ \\ ${ }^{1}$ Florida State University, FAMU-FSU College of Engineering, Department of Civil and Enviromental Engineering, Tallahassee, \\ FL 32306, USA \\ ${ }^{2}$ Florida State University, FAMU-FSU College of Engineering, Department of Industrial \& Manufacturing Engineering, \\ Tallahassee, FL 32306, USA
}

Correspondence should be addressed to MohammadReza Seyedi; reza.seyedi@fsu.edu

Received 19 July 2021; Revised 11 November 2021; Accepted 26 November 2021; Published 31 December 2021

Academic Editor: Arkatkar Shriniwas

Copyright (C) 2021 MohammadReza Seyedi et al. This is an open access article distributed under the Creative Commons Attribution License, which permits unrestricted use, distribution, and reproduction in any medium, provided the original work is properly cited.

\begin{abstract}
In this study, we selected four real-world rear-end crash scenarios with different crash characteristics. The vehicles involved in those crashes were not equipped with any crash avoidance systems. We then used the accident reconstruction method to build those crash scenarios in PC-Crash software. Then, different FCW/AEB safety algorithms have been defined for a subject vehicle model in each crash scenario and each scenario was simulated for a set of input parameters such as vehicle speed, brake intensity, and driver reaction time. The range and distribution of input parameters were extracted from the related field crash data and available literature. A total number of 16000 simulations have been conducted which produced input-output datasets for further investigations. Finally, the effects of input parameters on simulation outcomes including crash occurrence, AEB activation, injury risk, and vehicle damage have been quantified using the Boruta algorithm. The results indicated that the overall effectiveness of the AEB system was a $57 \%$ reduction of rear-end crashes, a 52\% reduction of injury severity (striking vehicle's passengers), and a $47 \%$ reduction of damages for striking vehicles. The results also showed that the available AEB algorithms were more effective for the average speed equal to or less than $80 \mathrm{kmph}$. The speed of the subject vehicle, type of AEB algorithm, sensor detection range, and driver reaction time were the most important parameters on crash outcomes. In addition, the results indicated that the performance of FCW had a direct impact on the effectiveness of the AEB system for the integrated FCW + AEB system.
\end{abstract}

\section{Introduction}

The advanced driver assistance systems (ADAS) technologies have shown promising results in terms of crash prevention and mitigation by providing contextual information to the driver such as a state of vehicle and traffic situation, controlling the vehicle dynamics, or warning the driver in high-risk situations, or recommending certain actions [1]. Among ADAS technologies, collision-avoidance systems including the autonomous emergency brake (AEB) and forward collision warning (FCW) have been specifically developed to prevent or mitigate rear-end and pedestrian collisions. The rear-end crashes are the most common type of crash and account for approximately $30 \%$ of the total crashes each year in the U.S. They mostly resulted from the driver's inattention or a short-distance car-following situation [2]. The National Transportation Safety Board estimated that over $80 \%$ of deaths resulting from rear-end crashes can be prevented by collision-avoidance systems [3]. The FCW system has been widely adopted in the market, whereas the AEB system is a somewhat new technology. For example, in 2016, the AEB system was optional for only $6 \%$ of vehicles and installed on $1 \%$ of vehicles in the USA; it is expected that automobile manufacturers make the AEB 
standard by 2022 [4]. This could potentially reduce the rearend crashes up to $70 \%$ if implemented on all passenger cars [5]. Figure 1 shows the car-following scenario where the subject vehicle (SV), equipped with AEB and FCW, detects the lead vehicle (LV) via systems such as radar, lidar, scanner, camera-laser device, or vehicle-to-vehicle communication technology [6]. When the system recognizes an impending collision, the FCW system warns a driver using visual, audio, or haptic interfaces to apply the brake. If the driver does not react in time and the crash is imminent, the AEB system automatically applies the full brake at a certain distance and time to stop the car.

Typically, the FCW/AEB systems are based on two main components: safety distance and time to collision (DTC and TTC). The DTC and TCC can be converted to each other based on the relative speed of vehicles. From this perspective, Wang and Chen et al. (2016) divided the FCW algorithms into perception-based and kinematics-based algorithms. The perceptual-based algorithms were empirical mathematical models that were developed based on the human perception threshold regarding the TTC. Parameters that are included in these models are the relative velocity of vehicles and SV vehicle's speed. On the other hand, the kinematic-based models use deceleration rate, driver reaction time, sensor's delay, and speed data to determine the DTC or TTC for the FCW/AEB activation. There have been several algorithms developed by researchers and vehicle manufacturers with commercial names such as Mazda, Honda, Jaguar, and the National Highway Traffic Safety Administration (NHTSA) algorithms [7]. Studies on FCW/AEB systems can be classified into the following areas:

(i) Algorithm studies (AS): they are also called vehicleperformance-based studies that focused on developing the FCW/AEB algorithms and evaluating their performance to control the longitudinal dynamics of the vehicle. The main purpose of AS studies was to gain a better understanding of the driver characteristics (e.g., reaction time and braking intensity), vehicle dynamic factors (e.g., tire-road interaction), detection, perception, and prediction technologies and then incorporating those factors into their algorithms to achieve the best performance of the FCW/AEB systems.

(ii) Effectiveness studies (ES): the main objective was to assess the effects of FCW/AEB systems on safety (e.g., reducing the crash number, injury severity, or crash severity), driver behavior (e.g., driver acceptance or driver reaction), and traffic conditions.

Table 1 lists the past studies on FCW/AEB systems and classifies them based on their approach and area of study. Not shown in the table, but these studies can also be classified as retrospective and prospective research according to Kovaceva et al. [55]. In retrospective assessment, researchers use realworld crash data such as the national crash database, insurance claims, or naturalistic driving data. The prospective approach, on the other hand, uses the computer simulation, field operation test, or driving simulator to assess the safety

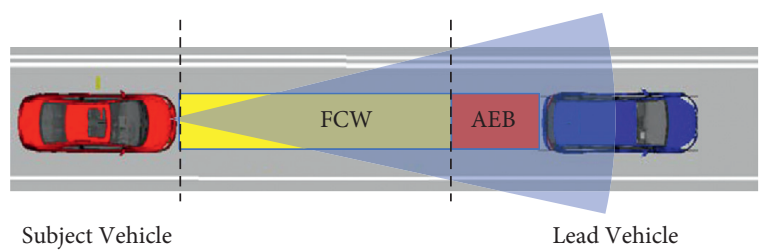

FIgURE 1: The FCW and AEB crash avoidance systems for carfollowing scenarios.

impacts. The retrospective approach is indeed the most effective way to evaluate the safety of these systems because it directly uses real-world crash data. However, the actual crash data for the vehicles equipped with AEB systems are nonexistent or very limited to specific vehicle models $[28,36]$. In addition, the information regarding the AEB systems is not usually available in the public domain crash database and needs a third party (vehicle manufacturers) to extract this information [49]. Therefore, it is difficult to distinguish between the vehicles with and without those systems.

Direct assessment of safety benefits using a prospective approach has been a challenge. Flannagan and LeBlanc [41] provided a detailed evaluation of FCW + AEB performance using the naturalistic driving data for 1021 passenger cars with no direct assessment of safety benefits. The driving simulator studies were focused only on FCW systems in order to characterize the driver behavior [45], improve the algorithm [20,35], or warning systems [2, 9]. Yue et al. [44] analyzed the results of recent studies that have been conducted on the effectiveness of different ADAS technologies. They estimated that the FCW + AEB system can potentially reduce the number of rear-end crashes by up to $50 \%$. They also emphasized the gaps that exist between the AS and ES studies in which studies that evaluate the relationship between the system performance and safety effectiveness of ADAS technologies are scarce. Therefore, our understanding of how factors including types of FCW/AEB algorithms, driver reaction, and road conditions can contribute to the variance of safety benefits of these systems is still limited.

Using analytical models and simulation combined with real-world field data has shown a great potential to address this challenge. Kusano and Gabler [21] and Kusano and Gabler [22] studied the safety effectiveness of FCW + AEB systems using field data and analytical analysis. The analytical parts were developed based only on speed change of vehicles $(\Delta V)$ that was available in the database which may not accurately represent the crash characteristics. The purpose of this paper is to establish a better understanding of the effects of FCW + AEB system parameters, driver behavior, and road conditions on vehicle performance and safety during the car-following scenario and quantify the relationship between them.

The remainder of this paper is organized as follows. In Section 2, we will explain the four major steps that have been taken to build the simulation scenarios based on real-world crash data. The simulation results are presented and evaluated in Section 3 followed by a discussion and limitation of this study. Finally, conclusions are given in Section 4. 
TABLe 1: Summary of research on FCW and AEB.

\begin{tabular}{|c|c|c|c|c|}
\hline Authors & Methods & ADAS systems & Area of study & Findings \\
\hline Brown et al. [8] & Analytical analysis & FCW & AS & $\begin{array}{l}\text { TTC and driver reaction time had the } \\
\text { most effects on FCW performance }\end{array}$ \\
\hline & & & & $\begin{array}{l}\text { For distracted drivers, early warning } \\
\text { reduced the number of collisions by }\end{array}$ \\
\hline Lee et al. [9] & Driving simulator & FCW & ES & $\begin{array}{c}80.7 \% \text { and its severity by } 96.5 \% \text {. The } \Delta \mathrm{V} \\
\text { for a subject vehicle was used to measure } \\
\text { the crash severity }\end{array}$ \\
\hline $\begin{array}{l}\text { Ervin and Sayer } \\
{[10]}\end{array}$ & Field operational test & FCW & $\begin{array}{l}\text { ES (safety + driver } \\
\text { acceptance) }\end{array}$ & $\begin{array}{l}\text { The rate and severity of traffic conflicts } \\
\text { did not change with or without FCW } \\
\text { systems, and the acceptance of FCW was } \\
\text { mixed due to the false alarms }\end{array}$ \\
\hline Lee and Peng [7] & Naturalistic driving data & FCW & AS & $\begin{array}{l}\text { Six FCW algorithms were analyzed based } \\
\text { on the kinematic data extracted from } 107 \\
\text { cases. The JHU APL algorithm developed } \\
\text { by NHTSA and John Hopkins showed } \\
\text { the best performance }\end{array}$ \\
\hline $\begin{array}{l}\text { Sugimoto and } \\
\text { Sauer [11] }\end{array}$ & Simulation & FCW & ES (safety) & $\begin{array}{c}38 \% \text { reduction in the total number of } \\
\text { crashes and } 44 \% \text { reduction in fatal } \\
\text { injuries }\end{array}$ \\
\hline $\begin{array}{l}\text { Najm and Stearns } \\
{[12]}\end{array}$ & Field operational test & $\begin{array}{l}\text { FCW + adaptive } \\
\text { cruise control }\end{array}$ & $\begin{array}{l}\text { ES (safety }+ \text { driver } \\
\text { acceptance) }\end{array}$ & $\begin{array}{l}8-23 \% \text { crash reduction for speed }<35 \\
\text { mph and } 11-26 \% \text { reduction for the } \\
\text { vehicle's speed }>35 \text {. Overall, this system } \\
\text { can reduce all rear-end crashes by } 10 \% \text {, } \\
\text { and the acceptance of FCW was mixed } \\
\text { due to the false alerts }\end{array}$ \\
\hline $\begin{array}{l}\text { Breuer and } \\
\text { Faulhaber [13] }\end{array}$ & Driving simulator & $\begin{array}{c}\text { Braking assistant } \\
\text { system }\end{array}$ & ES (safety) & $44 \%$ rear-end crash reduction \\
\hline $\begin{array}{l}\text { Jamson and Lai } \\
{[14]}\end{array}$ & Driving simulator & FCW & AS & $\begin{array}{l}\text { Introduced the adaptive FCW system } \\
\text { based on driver style }\end{array}$ \\
\hline Kullgren [15] & Field data and simulation & AEB & ES (safety) & $\begin{array}{l}44 \% \text { reduction of MAIS } 2+\text { injuries in } \\
\text { rear-end collisions for a reduced delta- } \mathrm{v} \\
\text { with } 10 \mathrm{kmph}\end{array}$ \\
\hline $\begin{array}{l}\text { Georgi and } \\
\text { Zimmermann [16] }\end{array}$ & Field data analysis & $\mathrm{FCW}+\mathrm{AEB}$ & ES (safety) & $\begin{array}{l}\text { Quantify the driver reaction based on } \\
\text { three types of drivers: realistic, best, and } \\
\text { lethargic. For the realistic driver, the AEB } \\
\text { decreased the rear-end crashes by } 72 \%\end{array}$ \\
\hline $\begin{array}{l}\text { Kuehn and } \\
\text { Hummel [17] }\end{array}$ & Field data analysis & $\mathrm{FCW}+\mathrm{AEB}$ & ES (safety) & $\begin{array}{c}5.7 \%-40.8 \% \text { reduction of all car crash } \\
\text { types based on a combination of active } \\
\text { safety systems }\end{array}$ \\
\hline $\begin{array}{l}\text { Mohebbi and Gray } \\
{[2]}\end{array}$ & Driving simulator & FCW & ES (driver acceptance) & $\begin{array}{c}\text { Evaluated the effectiveness of different } \\
\text { warning systems including tactile and } \\
\text { auditory on the distracted driver. They } \\
\text { found that the tactile warning is more } \\
\text { effective }\end{array}$ \\
\hline $\begin{array}{l}\text { Coelingh and } \\
\text { Eidehall }[18]\end{array}$ & Field operational test & $\mathrm{FCW}+\mathrm{AEB}$ & ES (safety) & $\begin{array}{c}\text { Evaluate the effectiveness of the systems } \\
\text { in velocity reduction and stopping } \\
\text { distance for the pedestrian crash } \\
\text { scenarios based on NHTSA test } \\
\text { procedures }\end{array}$ \\
\hline $\begin{array}{l}\text { Kusano and Gabler } \\
{[19]}\end{array}$ & $\begin{array}{c}\text { Field data }+ \text { analytical } \\
\text { analysis }\end{array}$ & AEB & ES (safety) & $\begin{array}{c}12 \%-50 \% \text { reduction of delta-v for the } \\
\text { subject vehicle } \\
\text { Up to } 14 \% \text { reduction of collisions } \\
19 \%-57 \% \text { reduction of injury }\end{array}$ \\
\hline Jermakian [5] & Field data analysis & FCW & ES (safety) & $\begin{array}{c}\text { FCW had the greatest potential to } \\
\text { prevent all crash types among other } \\
\text { systems including side view assist, lane } \\
\text { departure warning, and adaptive } \\
\text { headlights }\end{array}$ \\
\hline $\begin{array}{l}\text { Bella and Russo } \\
\text { [20] }\end{array}$ & Driving simulator & FCW & AS & $\begin{array}{l}\text { Evaluated different warning algorithms } \\
\text { and developed a new warning algorithm }\end{array}$ \\
\hline
\end{tabular}


TABle 1: Continued.

\begin{tabular}{|c|c|c|c|c|}
\hline Authors & Methods & ADAS systems & Area of study & Findings \\
\hline $\begin{array}{l}\text { Kusano and Gabler } \\
\text { [21] }\end{array}$ & Field data analysis & FCW & AS & $\begin{array}{l}\text { Data from EDR system of } 47 \text { rear-end } \\
\text { crashes were extracted to quantify the } \\
\text { driving reaction. The average brake level } \\
\text { was } 0.52 \mathrm{~g} \text { in } 1.1 \text { to } 1.4 \mathrm{~s} \text { before the crash }\end{array}$ \\
\hline $\begin{array}{l}\text { Kusano and Gabler } \\
{[22]}\end{array}$ & $\begin{array}{c}\text { Field data }+ \text { analytical } \\
\text { analysis }\end{array}$ & $\mathrm{FCW}+\mathrm{AEB}$ & ES (safety) & $\begin{array}{l}\text { Reduce the } \Delta \mathrm{V} 14 \%-34 \% \\
\text { Up to } 50 \% \text { reduction of fatal injuries } \\
\text { Up to } 7.7 \% \text { reduction of crash numbers }\end{array}$ \\
\hline $\begin{array}{l}\text { Isaksson-Hellman } \\
\text { and Lindman [23] }\end{array}$ & Field data analysis & $\mathrm{FCW}+\mathrm{AEB}$ & ES (safety) & $\begin{array}{c}\text { They used insurance data for specific car } \\
\text { models and found } 23 \% \text { rear-end crash } \\
\text { reduction }\end{array}$ \\
\hline $\begin{array}{l}\text { Anderson and } \\
\text { Doecke [24] }\end{array}$ & Simulation & AEB & ES (safety) & $\begin{array}{c}\text { Predicted the AEB system is highly } \\
\text { effective to reduce the risk of pedestrian } \\
\text { crashes }\end{array}$ \\
\hline $\begin{array}{l}\text { Chauvel and Page } \\
{[25]}\end{array}$ & Field data analysis & AEB & ES (safety) & $\begin{array}{c}\text { Up to } 15.3 \% \text { reduction of fatal pedestrian } \\
\text { crashes }\end{array}$ \\
\hline Rosen [26] & Field data analysis & AEB & ES (safety) & $\begin{array}{c}\text { Up to } 40 \% \text { reduction of injury severity for } \\
\text { the vulnerable road users }\end{array}$ \\
\hline $\begin{array}{l}\text { Rizzi and Kullgren } \\
\text { [27] }\end{array}$ & Field data analysis & $\mathrm{FCW}+\mathrm{AEB}$ & ES (safety) & $\begin{array}{l}\text { The low-speed AEB reduces the striking } \\
\text { rear-end crashes (speed area of } 50 \mathrm{~km} / \mathrm{h} \text { ) } \\
\text { by } 54-57 \% \\
\text { The overall reduction regardless of the } \\
\text { speed was } 35 \%-41 \%\end{array}$ \\
\hline $\begin{array}{l}\text { Doyle and } \\
\text { Edwards [28] }\end{array}$ & Field data analysis & AEB & ES (safety) & $\begin{array}{l}\text { Substantial claim prevention of the third } \\
\text { party } \\
8 \% \text { lower for own damage } \\
21 \% \text { lower third party injury }\end{array}$ \\
\hline $\begin{array}{l}\text { Fildes and Keall } \\
\text { [29] }\end{array}$ & Field data analysis & AEB & ES (safety) & $\begin{array}{c}38 \% \text { reduction of rear-end crashes } \\
\text { No differences in effectiveness between } \\
\text { various speeds }\end{array}$ \\
\hline $\begin{array}{l}\text { Flannagan and } \\
\text { LeBlanc [30] }\end{array}$ & Naturalistic driving data & FCW & AS (system performance) & $\begin{array}{c}\text { Provided detailed information about } \\
\text { alert events and driving exposure of } 1985 \\
\text { vehicles over a year. The most common } \\
\text { type scenarios that FCW was activated } \\
\text { were approaching slower or accelerating } \\
\text { vehicle }\end{array}$ \\
\hline $\begin{array}{l}\text { Grove and Atwood } \\
{[31]}\end{array}$ & Naturalistic driving data & $\mathrm{FCW}+\mathrm{AEB}$ & $\begin{array}{c}\text { AS (system } \\
\text { performance) }+\mathrm{ES} \\
\text { (driver acceptance) }\end{array}$ & $\begin{array}{c}\text { Studied the AEB performance of } 150 \\
\text { heavy vehicles and its effects on diver } \\
\text { behavior and quantified the situations for } \\
\text { false AEB activation }\end{array}$ \\
\hline Han and Heo [32] & Analytical analysis & $\mathrm{AEB}+\mathrm{FCW}$ & AS & $\begin{array}{l}\text { Improved the robustness of object } \\
\text { detection using the vehicle's kinematics }\end{array}$ \\
\hline $\begin{array}{l}\text { Isaksson-Hellman } \\
\text { and Lindman [33] }\end{array}$ & Field data analysis & $\mathrm{AEB}+\mathrm{FCW}$ & ES (safety) & $\begin{array}{l}47 \% \text { reduction for occupant injuries of } \\
\text { the struck vehicle }\end{array}$ \\
\hline $\begin{array}{l}\text { Rosado and Chien } \\
{[34]}\end{array}$ & Analytical analysis & AEB & AS & $\begin{array}{c}\text { Suggested the safety margin in terms of } \\
\text { time and distance for AEB }\end{array}$ \\
\hline $\begin{array}{l}\text { Wang and Chen } \\
{[35]}\end{array}$ & Driving simulator & FCW & AS & $\begin{array}{c}\text { Developed the kinematic-based } \\
\text { algorithm }\end{array}$ \\
\hline Cicchino [36] & Field data analysis & $\mathrm{FCW}+\mathrm{AEB}$ & ES (safety) & $\begin{array}{l}\text { The FCW + AEB reduced the rear-end } \\
\text { crashes by } 50 \% \text {. The rates of rear-end } \\
\text { crashes with injuries were reduced by } \\
56 \% \text { and } 59 \% \text { for striking and struck } \\
\text { vehicles, respectively }\end{array}$ \\
\hline Li and Xing [37] & Simulation & $\mathrm{FCW}+\mathrm{AEB}$ & ES (safety) & $\begin{array}{l}\text { Analyzed the adverse weather on } \\
\text { multirear-end crashes found that the } \\
\text { AEB is the most effective safety system to } \\
\text { reduce these types of crashes }\end{array}$ \\
\hline Lubbe [38] & Driving simulator & FCW & $\begin{array}{c}\text { AS (vehicle } \\
\text { performance) }+\mathrm{ES} \\
\text { (driver acceptance) }\end{array}$ & $\begin{array}{l}\text { Quantified the brake reaction time and } \\
\text { brake behavior and found the reaction } \\
\text { time for a heavily distracted driver is } 1 \mathrm{~s}\end{array}$ \\
\hline
\end{tabular}


TABle 1: Continued.

\begin{tabular}{|c|c|c|c|c|}
\hline Authors & Methods & ADAS systems & Area of study & Findings \\
\hline $\begin{array}{l}\text { Scanlon and } \\
\text { Sherony [39] }\end{array}$ & $\begin{array}{l}\text { Field data } \\
\text { analysis }+ \text { simulation }\end{array}$ & $\mathrm{FCW}+\mathrm{AEB}$ & ES (safety) & $\begin{array}{l}\text { The crash reduction in the intersection } \\
\text { with FCW was } 0-23 \% \text { and with AEB was } \\
25-59 \% \text {. Injury reductions were } 0-25 \% \\
\text { for FCW and } 38-79 \% \text { for the AEB system }\end{array}$ \\
\hline $\begin{array}{l}\text { Jermakian and Bao } \\
\text { [40] }\end{array}$ & Naturalistic driving data & FCW & ES (driving behavior) & $\begin{array}{c}\text { Waring can improve the lane-keeping } \\
\text { and turn-signal behaviors of teenage } \\
\text { drivers but may result in more close- } \\
\text { following behaviors }\end{array}$ \\
\hline $\begin{array}{l}\text { Flannagan and } \\
\text { LeBlanc [41] }\end{array}$ & Naturalistic driving data & $\mathrm{FCW}+\mathrm{AEB}$ & AS (system performance) & $\begin{array}{l}\text { They studied data from } 1021 \text { specific } \\
\text { vehicle models over a year to quantify the } \\
\text { AEB performance such as the } \\
\text { distribution of initial velocities where the } \\
\text { system was activated. Their indirect } \\
\text { safety assessment showed } 45 \% \text { reduction } \\
\text { of rear-end crashes }\end{array}$ \\
\hline $\begin{array}{l}\text { Sander and Lubbe } \\
\text { [42] }\end{array}$ & $\begin{array}{l}\text { Field data } \\
\text { analysis }+ \text { simulation }\end{array}$ & AEB & ES (safety) & $\begin{array}{l}\text { Evaluated field intersection crash data to } \\
\text { provide a set of scenarios that can be used } \\
\text { to assess the performance of AEB systems }\end{array}$ \\
\hline Wang and $\mathrm{Xi}[43]$ & $\begin{array}{c}\text { Naturalistic driving } \\
\text { data }+ \text { analytical analysis }\end{array}$ & $\mathrm{FCW}+\mathrm{AEB}$ & AS & $\begin{array}{l}\text { Developed a method to formulate the } \\
\text { driver's braking behavior from a } \\
\text { perception decision action perspective }\end{array}$ \\
\hline $\begin{array}{l}\text { Yue and Abdel- } \\
\text { Aty [44] }\end{array}$ & Driving simulator & FCW & AS & $\begin{array}{l}\text { They provided a comprehensive overview } \\
\text { of the research that has been conducted } \\
\text { on crash avoidance effectiveness and also } \\
\text { found that the FCW under the fog } \\
\text { condition can reduce } 35 \% \text { of near-crash } \\
\text { events }\end{array}$ \\
\hline $\begin{array}{l}\text { Wu and Abdel-Aty } \\
{[45]}\end{array}$ & Driving simulator & FCW & ES (driver behavior) & $\begin{array}{l}\text { Quantified the effects of fog conditions } \\
\text { on driver reaction and braking behavior } \\
\text { with the existence of the FCW system }\end{array}$ \\
\hline Lee and Jeong [46] & Field data analysis & AEB & ES (safety) & $25 \%$ injury reduction \\
\hline Zhao and Ito [47] & Simulation & AEB & AS + ES (safety) & $\begin{array}{c}\text { Conducted a series of simulations with } \\
\text { different AEB algorithm's parameters } \\
\text { and found the sensor angle is highly } \\
\text { effective to reduce the car-to-bicyclist } \\
\text { crashes }\end{array}$ \\
\hline $\begin{array}{l}\text { Arbabzadeh and } \\
\text { Jafari }[48]\end{array}$ & Naturalistic driving data & FCW & AS & $\begin{array}{c}\text { Estimate the driver reaction time based } \\
\text { on driver's characteristics to improve the } \\
\text { warning time }\end{array}$ \\
\hline $\begin{array}{l}\text { Flannagan and } \\
\text { Leslie [49] }\end{array}$ & Field data analysis & $\mathrm{FCW}+\mathrm{AEB}$ & ES (safety) & $\begin{array}{l}\text { They linked the police-reported crash } \\
\text { data with a vehicle identification number } \\
\text { and found that only FCW can reduce } \\
16 \% \text { reduction of rear-end crashes and } \\
\text { AEB (with ACC) can reduce the same } \\
\text { crash type by } 45 \%\end{array}$ \\
\hline Lei and Qin [50] & Simulation & $\mathrm{FCW}+\mathrm{AEB}$ & AS & $\begin{array}{c}\text { Developed a new algorithm to meet the } \\
\text { requirements of automobile safety and } \\
\text { comfort }\end{array}$ \\
\hline $\begin{array}{l}\text { Newstead and } \\
\text { Budd [51] }\end{array}$ & Field data analysis & AEB & ES (safety) & $\begin{array}{l}36 \% \text { reduction of fatal crashes for the } \\
\text { speed less than } 60 \mathrm{~km} / \mathrm{h} \text { and } 45 \% \text { for } \\
\text { speed above } 60 \mathrm{~km} / \mathrm{h}\end{array}$ \\
\hline $\begin{array}{l}\text { Salaani and } \\
\text { Elsasser [52] }\end{array}$ & Field operational test & $\mathrm{FCW}+\mathrm{AEB}$ & AS (system performance) & $\begin{array}{c}\text { Conducted test performance for heavy } \\
\text { vehicles }\end{array}$ \\
\hline $\begin{array}{l}\text { Wang and Zhong } \\
\text { [53] }\end{array}$ & Field data analysis & $\begin{array}{l}\text { All types of ADAS } \\
\text { technologies }\end{array}$ & ES (safety) & $\begin{array}{l}\text { Provide recommendations for what kind } \\
\text { of ADAS technology should be } \\
\text { prioritized based on countries crash data } \\
\text { Quantify the driver reaction when the }\end{array}$ \\
\hline $\begin{array}{l}\text { Zhu and Wang } \\
{[54]}\end{array}$ & Naturalistic driving data & FCW & $\begin{array}{l}\text { ES (driver } \\
\text { behavior }+ \text { traffic } \\
\text { conditions) }\end{array}$ & $\begin{array}{l}\text { FCW activated and the traffic conditions } \\
(1.3 \mathrm{~s} \text { was the mean value for driver } \\
\text { reaction time). The FCW can potentially } \\
\text { increase traffic efficiency }\end{array}$ \\
\hline
\end{tabular}




\section{Method}

This study is comprised of four major steps, as shown in Figure 2. In the first step, the four real-word rear-end crashes were reconstructed in PC-Crash software to obtain the impact characteristics. PC-Crash is vehicular accident simulation software that uses a single body with a total of 14 degrees of freedom [56]. The suspension system consists of four massless parallel springs and dampers. Note that the details of the mathematical models (for vehicle trajectory and impact mechanism) have been explored and their validity and accuracy were confirmed in several studies [57-61]. More information about the PC-Crash model and mathematical model of the impact are explained in Appendix A. The impact parameters extracted from crash reconstruction simulations were then used to calculate more informative properties including injury risk and vehicle damage. In step 2, the input variables including FCW/AEB algorithm parameters, driver reaction, and road condition were defined and output parameters regarding the safety effectiveness were specified. Next, building on four realworld crash simulation scenarios, a series of simulations with different types of FCW + AEB types and combinations were conducted (three different FCW + AEB algorithms and a benchmark with only the FCW system). Finally, by using the statistical analysis, the postprocessing step was devised to assess the effectiveness of AEB systems and the effects of input variables on outcomes.

2.1. Crash Reconstruction. Four real-world rear-end crashes that involved different vehicle types were selected to create the simulation scenarios. Table 2 presents general information on these crashes including the case number on the NHTSA database, environmental conditions, and vehicle's model. The environmental characteristics including road geometry and surface condition were modeled using the data available on accident reports. The overall vehicle motion and trajectory of each vehicle are illustrated in crash scene diagrams in Appendix A. There have been limitations regarding the physical evidence and available data in the field of accident reconstruction. However, for the purpose of this study, the available information was sufficient to obtain the impact parameters and required accuracy for the crash severity. In this study, the impact parameters were the body stiffness, contact friction between two vehicles, and restitution factor of the impact. The PC-Crash software has a built-in collision optimizer that can be used to calibrate the input parameters and find the optimum values for various input crash parameters. Further detailed information on the optimization process can be found in [56]. In the reconstruction process, the known parameters were the rest position, vehicle trajectory, and impact point which were estimated from the postcrash scene diagram and images. Then, a series (at least 1000 simulations) of Monte Carlo simulations were conducted considering uncertainties in parameters including vehicle's speed, road friction, contact friction, and restitution factors (see Appendix A). The optimum values of impact parameters provide sufficient accuracy for vehicle trajectory, rest position, and actual evidence, e.g., tire marks and postcrash vehicle's deformation [62]. It should be noted that the original four real-world rear-end crashes were reconstructed assuming that the vehicles were equipped with the antilock braking system.

It is important to note that the selection of these cases was based on several factors including the following: (1) the availability of crash information regarding the vehicles, location, accuracy of the crash diagram, and postcrash pictures of vehicle deformation; (2) the availability of vehicle dynamic information in PC-Crash library for the involved vehicles; (3) the rear-end crash must be the first and main harmful event of a crash and not the result of some other crashes or impacts. Therefore, by manually searching the NHTSA database and crash details, these four crashes were selected. Further explanation of how this selection of crash cases can affect the results is discussed in Section 3.

2.2. $A E B / F C W$ Algorithms. In this study, the FCW/AEB is considered as an integrated system that is based on two main components: the distance and time to collision (DTC and TTC) [6]. The mathematical equations for AEB and FCW algorithms are presented in Table 3. Depending on the algorithm, different parameters including vehicle's speed, maximum deceleration, driver reaction time, sensor delay (constant $0.2 \mathrm{~s}$ in this study), and safety margin were considered in their equations. One of the important parameters in the AEB algorithm is the value of the maximum possible deceleration (braking force) for SV and LV vehicles ( $a_{\mathrm{sv}}$ and $a_{\text {sv }}$ ). Studies considered different values ranged from $0.6 \mathrm{~g}$ to $1 \mathrm{~g}[18,21,35]$. However, it is well established that the maximum possible brake deceleration depends highly on the road-tire interaction [64]. In this study, instead of a constant number, we considered the maximum possible brake deceleration as a factor of crash scene coefficient of friction multiplied by gravitational constant $\left(\left(\mu_{\text {scene }}\right) \times g\left(9.81 \mathrm{~m} / \mathrm{s}^{2}\right)\right)$. This means that the selected AEB algorithms are capable to incorporate the real-time friction measurements into their algorithms and adapt the maximum deceleration rate of the vehicles based on road friction [65].

The $\mathrm{AL} \_\mathrm{K}$ algorithm was considered as an integrated FCW + AEB system that had the kinematics-based FCW system. Similarly, the AL_P was the FCW + AEB system with the perceptual-based FCW system and TTC $=2.2 \mathrm{~s}$. The benchmark AL_TCC was also selected that both FCW and AEB were based on the relative speed and TTC equal to $3.5 \mathrm{~s}$ and $1.5 \mathrm{~s}$, respectively. In the No_AEB case, the SV vehicle was equipped only with FCW with TTC $=2.2 \mathrm{~s}$ similar to the AL_P algorithm.

Figure 3 shows the typical time history of the speed resulting from a simulation of car-following scenarios with and without the crash. This figure is only for the illustration of how FCW and AEB systems affect the vehicle's speed for the case that the leading speed is stationary at the time of impact. We made the following assumptions during the development of rear-end simulation scenarios: (a) the driver of the SV vehicle does not react until the FCW system is 

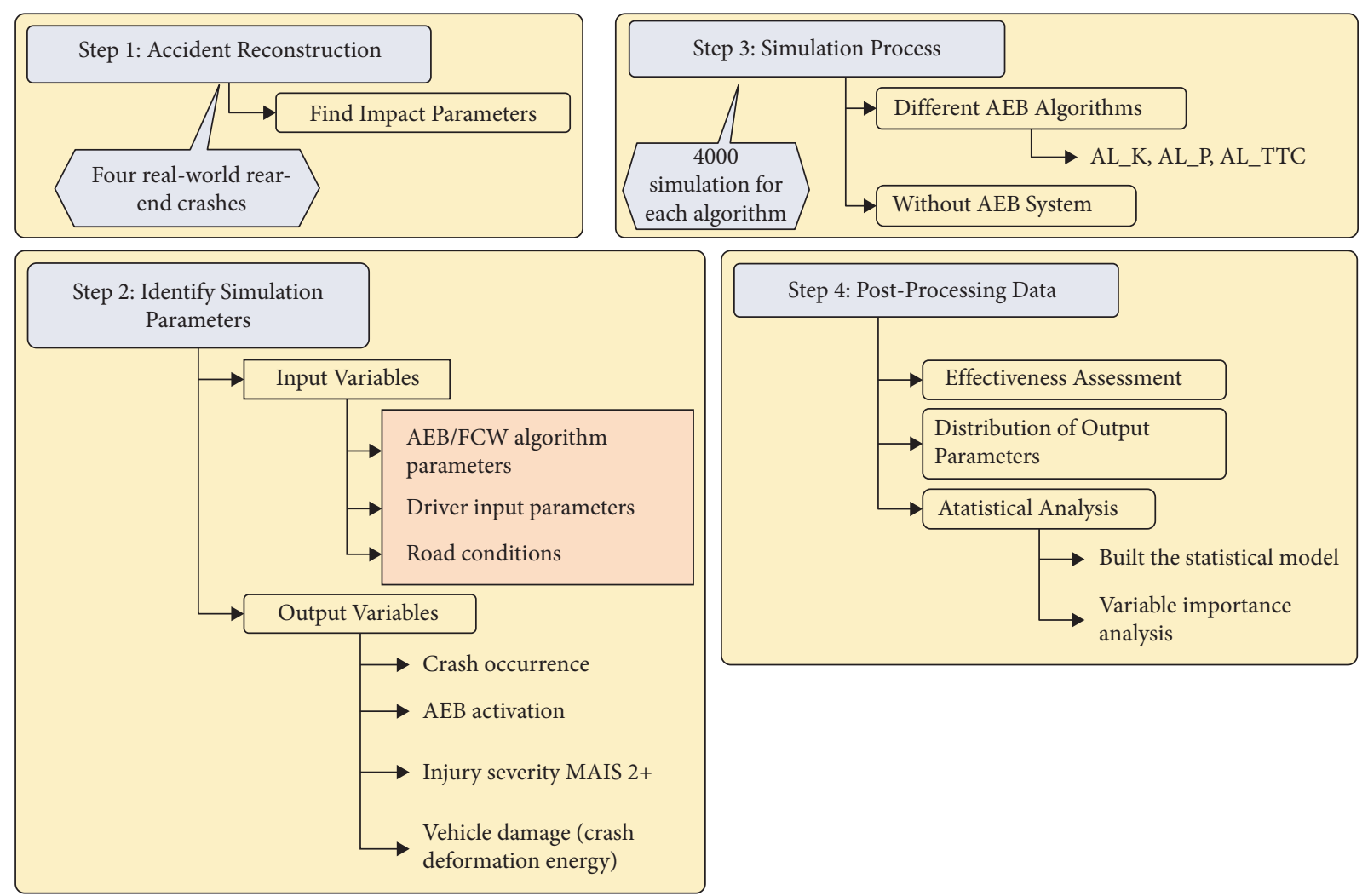

FIgURE 2: Research steps.

TABLE 2: Information of real-world rear-end crash cases.

\begin{tabular}{|c|c|c|c|c|c|c|}
\hline \multirow{2}{*}{ Simulation number } & \multirow{2}{*}{ NHTSA case number } & \multirow{2}{*}{$\begin{array}{l}\text { Road and weather } \\
\text { condition/speed limit }\end{array}$} & \multicolumn{2}{|c|}{ Subject vehicle } & \multicolumn{2}{|c|}{ Leading vehicle } \\
\hline & & & Body type & Mass (kg) & Body type & Mass $(\mathrm{kg})$ \\
\hline $\mathrm{C} 1$ & 3-C3-2018-006 & Dry and clear sunny/89 kmph & Pick-up truck & 2522 & Compact & 1571 \\
\hline $\mathrm{C} 2$ & 1-19-2016-069-03 & Dry and clear sunny/40 kmph & Sedan & 1550 & $\begin{array}{l}\text { Medium/heavy-duty } \\
\text { truck }\end{array}$ & 7120 \\
\hline $\mathrm{C} 3$ & $1-11-2018-035-01$ & \multirow{2}{*}{$\begin{array}{c}\text { Dry and clear sunny/56 kmph } \\
\text { Dry, clear, night light/105 } \\
\mathrm{kmph}\end{array}$} & Pick-up truck & 2404 & Sedan & 1470 \\
\hline $\mathrm{C} 4$ & $1-13-2018-048-01$ & & Pick-up truck & 2522 & Sedan & 1571 \\
\hline
\end{tabular}

TABLE 3: FCW and AEB algorithms.

\begin{tabular}{lccc}
\hline Algorithm & Source & FCW & AEB \\
\hline AL_K & {$[35]$} & $R_{w}=V_{s v}\left(t_{r}+t_{s}\right)+0.5\left(\frac{V_{s v}^{2}}{a_{s v}}-\frac{V_{l v}^{2}}{a_{l v}}\right)+R_{\text {min }}$ & $R_{b}=V_{r e l}\left(t_{r}+t_{s}\right)+0.5 \times a_{l v} \times\left(t_{r}+t_{s}\right)^{2}$ \\
AL_P & {$[35,63]$} & $R_{w}=V_{r e l} \times 2.2+R_{\min }$ & If $\frac{V_{l v}}{a_{l v}} \geq t_{s} R_{b}=V_{r e l}\left(t_{s}\right)+\left(t_{r} t_{s}\right) a_{l v}+0.5 \times 7.8\left(t_{r}\right)^{2}$ \\
AL_TTC & {$[17]$} & $R_{w}=V_{r e l} \times 3.5+R_{\min }$ & $V_{s v}\left(t_{s}\right)-0.5 \times a_{l v} \times\left(t_{r}-t_{s}\right)^{2}-0.5 \times \frac{V_{l v}}{a_{l v}}$ \\
No_AEB & {$[35]$} & $R_{b}=V_{r e l} \times 1.5$ & N/a \\
\hline
\end{tabular}

$V_{s v}:$ subject vehicle speed $(\mathrm{m} / \mathrm{s}) ; V_{l v}:$ lead vehicle speed $(\mathrm{m} / \mathrm{s}) ; V_{r e l}:$ relative speed, $\left(V_{s v}-V_{l v}\right) ; R_{\min }:$ safety margin $(\mathrm{m}) ; t_{r}:$ driver reaction $(\mathrm{s}) ; t_{s}:$ sensor delay $(\mathrm{s}) ; a_{s v}$ : maximum deceleration of subject vehicle $\left(\mathrm{m} / \mathrm{s}^{2}\right) ; a_{l v}$ : maximum deceleration of leading vehicle $\left(\mathrm{m} / \mathrm{s}^{2}\right)$; maximum possible deceleration of vehicle: $a_{\text {max }}=\mu_{\text {scene }} \times g$.

activated (@ $t_{\mathrm{w}}$ ); (b) the deceleration rate of both vehicles is constant without any jerk and the maximum deceleration of SV and LV vehicles is equal $\left(a_{\mathrm{sv}}=a_{\mathrm{lv}}\right)$; (c) the LV vehicle applies the maximum brake right at the beginning of simulation; (d) the AEB system activated at all speeds. As shown in Figure 3, the time history of the LV vehicle's speed decreases with the rate of $a_{\mathrm{lv}}$ until the stopping point. Meanwhile, the SV vehicle starts the simulation with 

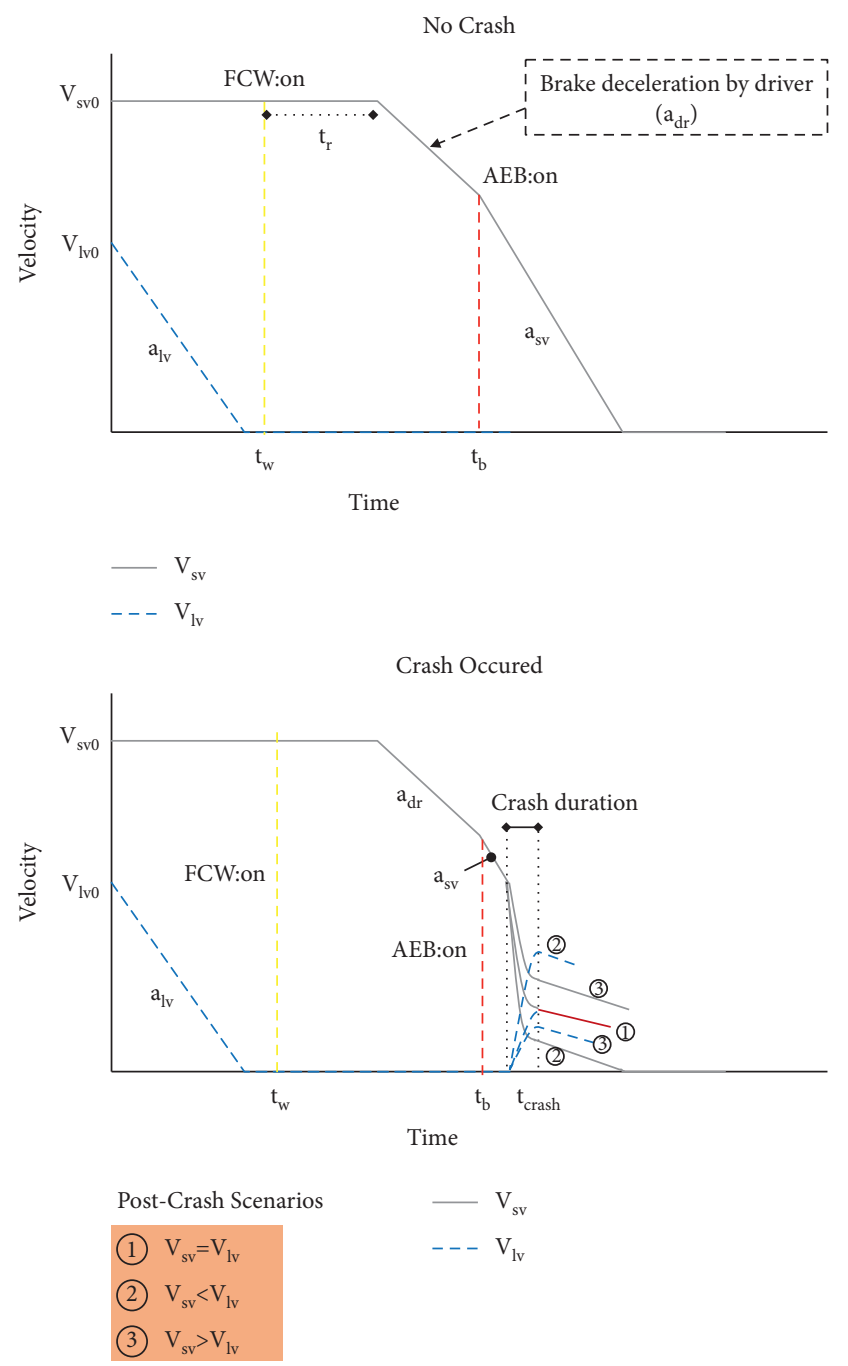

Figure 3: The time history of velocity for the subject and lead vehicles in the typical car-following situation for the crash and noncrash scenario. (a) No crush. (b) Crush occurred.

constant speed to the point that warning is activated. Then, based on driver reaction time $\left(t_{\mathrm{r}}\right)$, a driver applies the brake (the intensity of brake is not necessarily the maximum) which decreases the $V_{\mathrm{sv}}$ with the $a_{\mathrm{dr}}$ rate. At the time of AEB activation $\left(t_{b}\right)$, the maximum full brake deceleration is applied to stop the vehicle $\left(a_{\mathrm{sv}}\right)$. For the cases that a rear-end crash happens, both vehicles follow similar sequences up to the impact point. At this moment $\left(t=t_{\text {crash }}\right)$, the speed of both cars was suddenly changed, and depending on impact characteristics, three different postcrash scenarios can happen which are illustrated in Figure 3.

2.3. Simulation Process. The simulation process comprised of simulating four reconstructed crash scenarios with a specified range and distribution of input parameters and measuring the simulation outcomes for a different combination of FCW/AEB systems. It is crucial to define and specify the type of input parameters, their range, and distribution in which they reflect the real-world rear-end crash characteristics. Therefore, the crash data from the Crash
Injury Sampling System (CISS) between 2016 and 2018 were used to obtain the parameter's characteristics. The CISS is a weighted database on a nationally representative sample of crashes that has details about crash sites, vehicles, and passengers. Considering the weight factor, the total number of data points for rear-end crashes was found equal to 700,000 cases. This is enough to quantify the distribution of SV vehicle speed, environmental conditions, and the driver's reaction before the first harmful event. The TRAV_SP, WEATHER, and P_CRASH3 variables were used to find the vehicle's speed, weather condition, and driver input. The weather condition was used to estimate road friction. The details of input parameters, their range, and distributions are listed in Table 4.

The specified speed range was different from the range obtained from field data for two reasons: (1) the speed data reported CISS database is typically referred to as the speed right before the crashes, whereas our simulations start a few seconds before the crash; (2) the specified speed range [0-200 kmph] can represent a much wider range of speed limits. Based on CISS data, the weather condition for rearend crashes occurred in the dried clean road for $72 \%$ cases, $15 \%$ in cloudy weather, $10 \%$ in rainy weather, and $0.5 \%$ in snowy conditions. The random sampling with the same distribution was used to generate the road friction values $(\mathrm{Mu})$. The road friction for different road surface conditions ranged from 0.3 for a snowy road to 0.9 for dried road conditions [22]. The P_CRASH3 provides information about the driver's reaction (i.e., braking, steering, or acceleration) before the crash. Based on the data for the SV vehicle, the SV driver applied the brake in $70 \%$ of cases, and in $30 \%$ of cases, other actions were considered as no brake. For the LV vehicle, in $96 \%$ of cases, the driver did not take any action before the crash and applied the brake only in 3\% of cases. These probabilities were used to generate the random values for the qualitative variable ( $B_{\mathrm{r} \_}$inp) for driver input. For the driver reaction time, the gamma distribution by Kusano and Gabler [22] was used. They specified three different types of drivers including an alerted driver with reaction time ( $\operatorname{tr}$ ) less than $0.6 \mathrm{~s}$, a typical driver with a reaction time ranging from $0.6 \mathrm{~s}$ to $1.4 \mathrm{~s}$, and a distracted driver with a reaction time higher than $1.4 \mathrm{~s}$. The safety margin was selected based on the range of values found in the literature [20]. The other parameters including the detection range and braking intensity of the uniform distribution were selected because it was not feasible to quantify their value using CISS data.

After generating the input parameters with the random values and defined range and distributions, the output parameters were measured based on the following (see Table 5). The output parameters were crash occurrence (1: yes; 0 : no), the crash severity using crash deformation energy, injury severity using the maximum abbreviate injury scale (MAIS 2+), activation of safety AEB\&FCW systems (1: yes; 0 : no), and activation range for the FCW $\left(R R_{w}\right)$ and AEB $\left(R_{b}\right)$ systems. The crash occurrence and its severity were extracted from the impact characteristics resulting from the simulation (see Appendix A). The crash deformation energy is a typical metric to calculate the impact severity in the field of 
TABLE 4: Input parameters and their distribution.

\begin{tabular}{|c|c|c|c|}
\hline Input variable & Variable name & [Range] unit & Distribution \\
\hline Subject vehicle's speed & $V_{s v}$ & [0-200] kmph & $\begin{array}{c}\text { Gamma distribution } \\
(\text { shape }=5.78854313, \text { rate }=0.070391)\end{array}$ \\
\hline Leading vehicle's speed & $V_{l v}$ & {$[0-50] \mathrm{kmph}$} & Uniform \\
\hline Initial distance & $R_{d}$ & {$[30-120] \mathrm{m}$} & Uniform \\
\hline Safety margin & $R_{\min }^{a}$ & {$[6,9,12,15] \mathrm{m}$} & Uniform \\
\hline Road friction & $\mathrm{Mu}$ & {$[0.3-0.9]$} & $\begin{array}{l}\text { Normal }(\text { mean }=0.65, \\
\qquad \mathrm{sd}=0.1)\end{array}$ \\
\hline Braking intensity deceleration & Br_L & {$[3-9] \mathrm{m} / \mathrm{s}^{2}$} & Uniform \\
\hline Maximum brake intensity & Br_F & {$[3-9] \mathrm{m} / \mathrm{s}^{2}$} & Normal $($ mean $=6.4, \mathrm{sd}=1)$ \\
\hline Driver's reaction time $\left(t_{r}\right)$ & $t_{r}$ & {$[0.26-2.5] \mathrm{s}$} & $\begin{array}{l}\text { Gamma distribution } \\
(\text { shape }=7, \text { rate }=7)\end{array}$ \\
\hline Driver brake & Br_inp & [1: yes; $0:$ no] & $\begin{array}{c}\text { In } 70 \% \text { cases, "yes," } \\
\text { and in } 30 \% \text { cases, "no" }\end{array}$ \\
\hline Type of FCW/AEB algorithm & ADAS & AL_K, AL_P, AL_TTC, No_AEB & $\mathrm{N} / \mathrm{a}$ \\
\hline
\end{tabular}

TABLE 5: Output parameters measured from the simulations.

\begin{tabular}{lc}
\hline Output parameters (variable name) & Definition \\
\hline Crash occurrence (crash) & 0: no crash; 1: rear-end crash occurred \\
Crash deformation energy (E) & The vehicle damage measured using impact parameters \\
Injury severity (MAIS 2+) & Maximum abbreviated injury scale measured directly from $\Delta \mathrm{V}_{\text {sv }}$ \\
AEB activation (AEB) & $0:$ off; $1:$ on \\
Warning range $\left(R_{w}\right)$ & DTC for FCW activation \\
Brake range $\left(R_{b}\right)$ & DTC for AEB activation \\
Warning time $\left(t_{w}\right)$ & TTC to activate the FCW \\
Brake time $\left(t_{b}\right)$ & TTC to activate the AEB \\
\hline
\end{tabular}

DTC: distance to collision; TTC: time to collision

accident reconstruction $[66,67]$. To measure the MAIS $2+$ injury risk, Kusano and Gabler [19] proposed an equation based on the change of velocity $\left(\Delta V_{\mathrm{sv}}\right)$ and seatbelt status using the field data analysis:

$$
\text { MAIS } 2+=\frac{1}{1+e^{-\left(\beta_{0}+\beta_{1} \Delta V+\beta_{2}(b e l t)\right)}},
$$

where $\beta_{0}, \beta_{1}$, and $\beta_{2}$ were $-6.068,0.1$, and 0.6234 , respectively. belt is an indicator, taking on a value of 1 for a belted driver and 0 for an unbelted driver. The activation of FCW and AEB was also calculated based on the SV vehicle's position at each time step. Vehicle's relative speed and distance were measured from algorithms. If during the simulation, the vehicle passes the warning and braking range, the value of 1 is assigned to the FCW and AEB status. The corresponding TTC for FCW and AEB was also measured based on the following equations:

$$
t_{w}=\frac{R_{w}}{V_{r e l}} \& t_{b}=\frac{R_{b}}{V_{r e l}} .
$$

Figure 4 shows the process in each scenario that has been programmed using coupled simulation by Visual Basic and PC-Crash software. At the beginning of the simulation, the initial values were assigned to input parameters. Two conditions were set based on the rear-end crash dynamics. First, the simulation does not start if either the initial speed of SV vehicle was less than LV vehicle or the relative speed of cars was less than $4 \mathrm{~m} / \mathrm{s}$. This is because, in both of those situations, the likelihood of a rear-end crash is very low [43]. For the set of data that met the conditions, the SV vehicle was positioned at the distance $R_{d}$ from the lead vehicle. This way, the simulation starts right at the time that the following vehicle detects the leading vehicle. At each time step, the relative distance of the vehicles, warning range $\left(R_{w}\right)$, and braking range $\left(R_{b}\right)$ were calculated. Depending on the SV vehicle's initial position $\left(R_{\mathrm{d}}\right)$, specific sequences were defined based on the driver reaction time, braking behavior, and FCW/AEB status. Since these actions are sequential, the initial relative distance of vehicles determines the sequence of events. For example, if the initial distance is greater than the warning range, the vehicle continues to move forward without any driver's reaction until it reaches the $R_{\mathrm{w}}$ distance. Then, the FCW system is activated, and based on driver inputs (brake exertion, its intensity, and reaction time), the SV decelerates or continues to move forward up to the $R_{\mathrm{b}}$ distance. At this point, regardless of the driver's reaction, the full automated brake is applied to stop the vehicle.

For the cases that the initial SV's position is within the warning range $\left(R_{\mathrm{b}}<R_{\mathrm{d}}<R_{\mathrm{w}}\right)$ or shorter than the brake range $\left(R_{\mathrm{d}}<R_{\mathrm{b}}\right)$, the sequences of events were different. The first scenario is typical in a real-world traffic situation where the vehicles in other lanes perform a lane change in front of the SV vehicle or the SV vehicle does the lane change. In the first scenario, if driver input was not zero and the reaction time was not longer than the time that the subject vehicle needs to reach the $\mathrm{Rb}$ distance, the vehicle decelerates. If there was no driver input, the vehicle continues to move forward up to $\mathrm{Rb}$ 

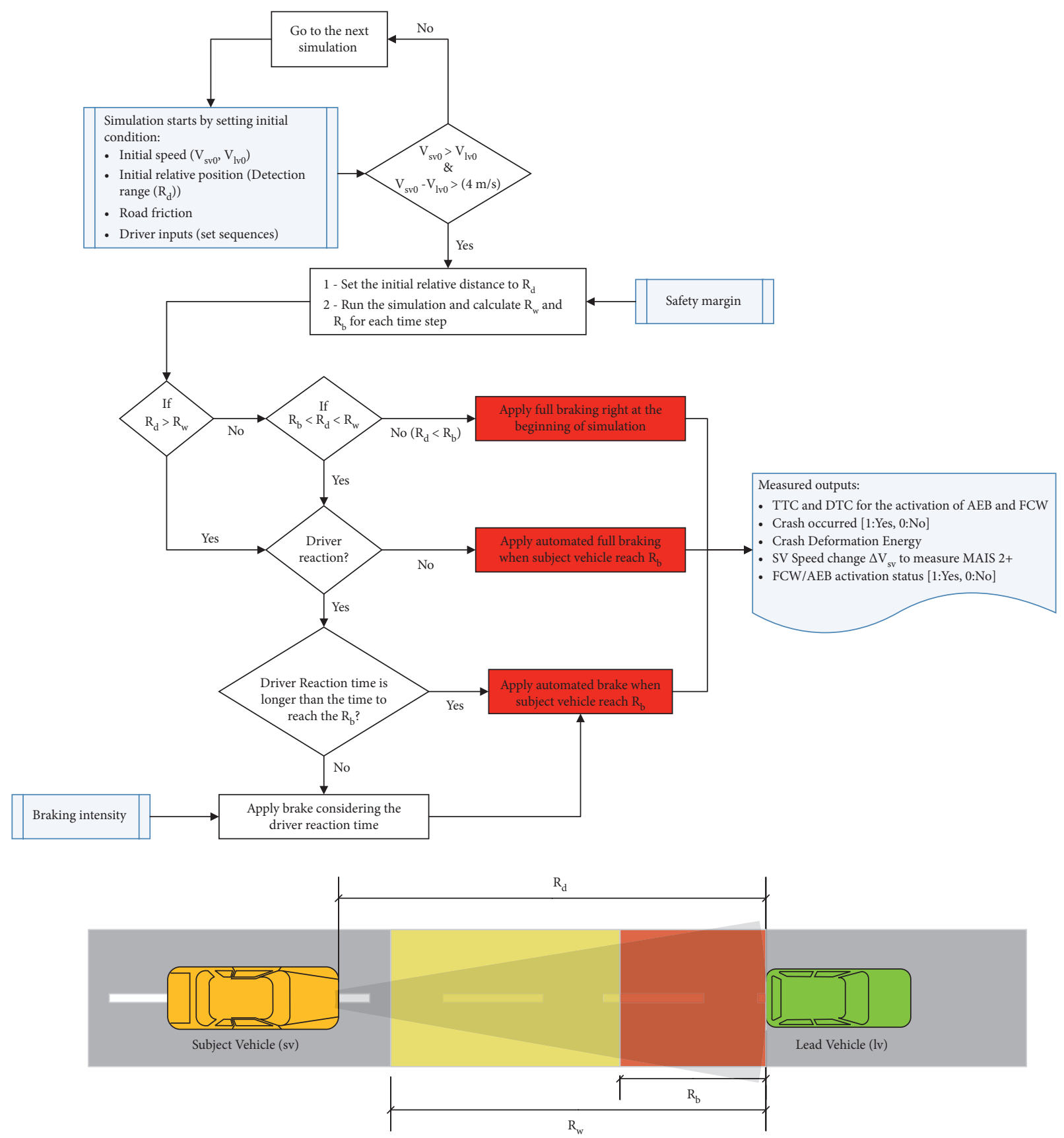

FIgURE 4: The simulation process.

distance. The latter scenario is less common and can happen for the same reason as the first scenario. In this case, the AEB is activated and the beginning of the simulation and the SV applies the full brake to stop the vehicle regardless of driver input.

For each reconstructed crash case, four combinations of active safety features including three different AEB systems $\left(\mathrm{FCW}+\mathrm{AL} \_\mathrm{K}, \mathrm{FCW}+\mathrm{AL} \_\mathrm{P}\right.$, and $\left.\mathrm{FCW}+\mathrm{AL} \_\mathrm{TTC}\right)$ and one without the AEB system (No_AEB) were selected. For each combination, 1000 scenarios were defined and simulated using the specified range and distribution of input parameters. Therefore, the total number of simulations generated for each safety feature was 4,000 cases.
2.4. Statistical Analysis of the Effects of Safety Features. In this step, we conducted a multivariable regression modeling and analysis methodology to estimate the effects of the various driver- and road-related variables (driver reaction time, road friction, etc.) and ADAS safety features (AEB, FCW, etc.) on the response variables of occurrence of a crash, AEB activation, vehicle damage, and injury severity. Since the occurrence of the crash and AEB activation are (0/1) binary variables, we used a binomial logit general linear model to quantify the effects. Energy absorption and injury severity are both continuous variables; thus, we utilized an ordinary least squares linear regression model to quantify the effects on these variables [68]. The proposed multivariable 
regression model approach allows us to study the effects of the type of FCW/AEB algorithm, driver reaction, and road conditions on the safety effectiveness of these systems. The regression modeling and the statistical analysis were conducted using $R$ software [69].

The coefficients of regressor variables for different responses will be different depending on the unit of the response; therefore, standardization of the effects is needed to determine which variables are more important for the response. The well-known Boruta algorithm [70] was used to quantify the importance of the regressor variables following the statistical models. Using the Boruta package in the $R$ software algorithm, we intended to capture the most important variables with respect to the outcomes [71]. Finally, the effectiveness of each FCW/AEB algorithms on different safety aspects was quantified using

$$
\text { eff }=1-\frac{P_{\text {with }}}{P_{\text {without }}},
$$

where the $P_{\text {with }}$ and $P_{\text {without }}$ are the probabilities of each outcome with and without the AEB system.

\section{Results and Discussion}

This section is presented in three separate parts: (1) results of simulations; (2) results of statistical analyses; and (3) limitations of this study. In Section 3.1, the simulation outcomes for each safety feature are presented based on the following aspects: the system performance measurements including the AEB activation and corresponding DTC and TTC to activate the AEB and FCW systems; the safety performance metrics the crash occurrence, injury risk (MAIS $2+>10 \%$ ), and vehicle damage $(E>100,000 \mathrm{~J})$. Then, the results of statistical analysis are presented in Section 3.2 to evaluate the relationship between the various input parameters, safety performance metrics, and AEB activation.

3.1. Results of Simulations. The performance of each algorithm (AL_K, AL_P, AL_TTC, and No_AEB) was evaluated in each reconstructed rear-end crash scenario. From the 4,000 simulations for each algorithm, the outcomes were measured for 3,548 cases, and in 452 cases, the simulation stopped for the following reasons. The relative speed of the two vehicles was very small $\left(V_{\mathrm{sv}}-V_{\mathrm{lv}}<4 \mathrm{~m} / \mathrm{s}\right)$ or the LV vehicle's speed was higher than the SV vehicle's speed $\left(V_{\mathrm{lv}}>V_{\mathrm{sv}}\right)$. Table 6 summarizes the distribution of the DTC and TTC and the activation rate of FCW and AEB systems for each algorithm. The typical ranges of $t_{\mathrm{w}}$ found in the literature for the rear-end crash scenarios are ranged from $2 \mathrm{~s}$ to $5 \mathrm{~s}[2,72,73]$, whereas for the AEB activation, the $t_{\mathrm{b}}$ values of $0.45 \mathrm{~s}$ to $0.6 \mathrm{~s}$ [19], $1 \mathrm{~s}$ to $2 \mathrm{~s}[17,24,26]$, and $1.5 \mathrm{~s}$ $-2.4 \mathrm{~s}$ for heavy vehicles [52] were used in the literature. In addition, the distribution of TTC for FCW and AEB activation based on different safety margins and types of the algorithm is presented in Figures 5 and 6.

Figure 7 shows the results of safety performance for each type of algorithm. As expected, the crash outcomes in terms of both number and severity were significantly higher when the
SV vehicle was equipped only with the FCW system (No_AEB). For instance, the rear-end crash rate of $80 \%$ resulted from simulations that were at least two times higher than cases with FCW + AEB. As pointed out by Yue et al. [44], the combined ADAS technologies seem more effective than a separate system. The AL_K algorithm showed the minimum crash outcomes in both crash number and crash severity. This algorithm had the highest average waring range $\left(R_{\mathrm{w}}=93.5 \mathrm{~m}\right.$ and $\left.t_{\mathrm{w}}=3.8 \mathrm{~s}\right)$ and the lowest braking range $\left(R_{\mathrm{b}}=30.2 \mathrm{~m}\right.$ and $\left.t_{\mathrm{b}}=1.35 \mathrm{~s}\right)$. On the other hand, AL_P safety performance results indicated the highest crash outcomes among AEB algorithms. The estimated TTC for the FCW and AEB activation by this algorithm were $2.7 \mathrm{~s}$ and $1.49 \mathrm{~s}$, respectively. The TTC of $2.7 \mathrm{~s}$ for FCW activation provided a shorter time for a diver to react and led to a higher number of crashes in the simulations with the AL_P algorithm. Lee and Peng [7] pointed out that these algorithms might have been designed based on different philosophies such as preventing all rearend crashes or only crash mitigations. However, the results for the AL_P indicated that this algorithm did not perform well in any of those aspects.

In addition, the unavoidable crash cases for the SV vehicle equipped with the AEB system were extracted. The results showed that the crash occurred in the cases where the SV vehicle had an average velocity of $111 \mathrm{kmph}$, the LV vehicle's speed of $24 \mathrm{kmph}$, the initial distance of $59 \mathrm{~m}$ (ranged mostly between $R_{b}<R_{d}<R_{w}$ ), and the driver reaction time around $1.1 \mathrm{~s}$. This introduces the high-risk scenario that can be potentially used as a test scenario to evaluate the AEB performance in a car-following scenario.

Figure 8 shows the results of the safety effectiveness assessment for each algorithm and the overall results. The greatest potential safety benefits come from the AL_K algorithm in crash reduction, injury severity, and vehicle damage of $69 \%, 62 \%$, and $60 \%$, respectively. As mentioned earlier, there have been several studies that estimated the safety effectiveness in crash reduction ranged from 30\% [27] to $79 \%$ [16] which depends on different factors such as assessment method, type of FCW/AEB algorithms, and speed range. Regardless of the type of algorithm, the overall effectiveness assessment of the AEB system showed a $57 \%$ reduction in rear-end crash numbers, $52 \%$ reduction in SV vehicle damage, and $45 \%$ reduction in risk of MAIS $2+$ injury.

The only study on the effectiveness of AEB systems regarding the vehicle damage was conducted by Doyle et al. [28] using the insurance claim data for specific vehicle models. They pointed out that the AEB system can effectively reduce the vehicle's damage ranging between $6 \%$ and $18 \%$. However, they did not include factors such as vehicle speed, types of AEB algorithm, and driver's characteristics in their statistical model. The presented study showed an average of $52 \%$ reduction in vehicle damage based on the crash deformation energy calculated directly from the impact mechanics. Our evaluation with respect to the effectiveness of $\mathrm{AEB}$ to reduce the injury risk is consistent with the findings of multiple studies. Kusano and Gabler [22] and Cicchino [36], for example, estimated $50 \%$ and $56 \%$ injury reduction in their analysis, respectively. 
TABLE 6: The summary of AEB and FCW performance regarding the DTC, TTC, and activation rate for the AEB and FCW algorithms.

\begin{tabular}{lcccccc}
\hline Algorithm & $R_{\mathrm{w}}(\mathrm{m})^{*}$ & $R_{\mathrm{b}}(\mathrm{m})^{*}$ & $t_{\mathrm{w}}(\mathrm{s})^{*}$ & $t_{\mathrm{b}}(\mathrm{s})^{*}$ & AEB activation $(\%)$ & FCW activation $(\%)$ \\
\hline AL_K & $93.5(55.66)$ & $30.2(13.83)$ & $3.8(1.03)$ & $1.35(0.48)$ & 81 & 100 \\
AL_P & $60.2(18.6)$ & $34(13.2)$ & $2.72(0.26)$ & $1.49(0.15)$ & 94 & 100 \\
AL_T & $90.2(29.3)$ & $34.1(12.4)$ & $4.1(0.26)$ & 1.5 & N/a & 100 \\
No_AEB & $57.5(18.15)$ & N/a & $3(0.58)$ & N/a & N/a & 100 \\
\hline
\end{tabular}

* mean standard deviation.

3.2. Results of Statistical Analysis. Table 7 presents the details of four statistical models that were developed for crash occurrence, AEB activation, injury risk, and vehicle damage. The results show an acceptable accuracy for each model based on the value of R-squared $\left(R^{2}\right)$ and the corresponding $p$ value. All the input variables except the road friction were significant in crash, injury, and vehicle damage models. This is because we incorporated the realtime road friction measurements into our algorithms which is advantageous to the system [74]. Also, in the crash model, the $\mathrm{Mu}$ and $V_{\mathrm{lv}}$ were not significant based on a $90 \%$ confidence interval.

Using the Boruta library in $R$ software, the most important variables with respect to the statistical models are presented in Figure 9. The results show that the most important parameters on AEB activation, crash, injury, and energy model were the subject vehicle's speed $\left(V_{\mathrm{sv}}\right)$, types of the algorithm (ADAS), initial distance or detection range $\left(R_{d}\right)$, and driver's reaction time $\left(t_{r}\right)$. However, the level of importance for each parameter was different in each model. For example, in the AEB activation model, the SV vehicle's speed had the highest level of importance, whereas in the crash model, the type of FCW/AEB system (ADAS) had the highest importance. The results also showed that the injury model mostly depends on the $V_{\mathrm{sv}}$. This is because the velocity change $\left(\Delta V_{\text {sv }}\right)$ was the metric to calculate the injury severity which its value depends on impact characteristics (e.g., restitution factor and body stiffness). The following paragraphs will explain the effect of these important parameters on the statistical models.

Figure 10 shows how different parameters affect the AEB activation. The AL_P algorithm had the highest activation rate compared to other algorithms. Also, increasing the initial distance (sensor range) from $50 \mathrm{~m}$ to $75 \mathrm{~m}$, decreases the AEB activation by $10 \%$. When the SV speed is higher than $100 \mathrm{kmph}$, AEB is activated with almost $100 \%$ probability. Also, increasing the driver reaction time will increase the AEB activation rate. The activation rate is more than $95 \%$ for the driver reaction time of $1.1 \mathrm{~s}$ and more. Although the current AEB algorithms incorporate the driver's reaction time in their mathematical models, in most cases, they use a fixed value, whereas, depending on driver style, age, and gender, location of the reaction time can change [14]. The results show that for the integrated FCW + AEB system, the performance of FCW can significantly affect the performance of AEB. As mentioned earlier, even though the AL_P algorithm predicted a similar range of DTC and TTC for AEB activation, the low value of TTC for FCW $\left(t_{w}=2.7 \mathrm{~s}\right)$ led to a higher number of crashes compared to other algorithms.
Figure 11 shows the effects of type of algorithm (ADAS), SV vehicle's speed, initial distance (sensor range), and driver reaction time on the crash probability. Regarding the effect of ADAS algorithms on crash probability, we can see that AL_K is most effective, followed by the AL_TTC which in turn is followed by the AL_P system. This is consistent with the safety effectiveness assessment results that are shown in Figure 8. To our knowledge, there has not been a study that assessed the safety effectiveness regarding the safety model of FCW/AEB algorithms. The results indicated that decreasing the SV vehicle's speed and driver reaction time can significantly decrease the risk of crashes. Additionally, increasing the initial distance (sensor range) from $50 \mathrm{~m}$ to $100 \mathrm{~m}$ can potentially decrease the risk of crashes by $35 \%$.

There have been several studies about the effectiveness of AEB systems regarding the vehicle's speed. Figure 12 shows the distribution of the speed for the SV vehicle equipped with AEB systems regarding the crash occurrence. The results indicate that the selected AEB systems are more effective to avoid crash for the average speed of $75 \mathrm{kmph}$ and ineffective for the average speed of $111 \mathrm{kmph}$ and higher. This is consistent with the results of the field data analysis extracted by Cicchino [36]. She found out that the AEB system is more effective for a speed of $80 \mathrm{kmph}$ or less. Also, Rizzi et al. [27] studied the low-speed AEB for specific car models and found that the reduction of rear-end crashes was significant at the speed of $50 \mathrm{kmph}$. The findings of this study support the fact that the safety performance of current FCW/ AEB systems highly depends on the vehicle's speed, as shown in effect plots of the crash, injury, and energy models (see Figures 11 and 13). The results of the crash based on the type of AEB algorithm and SV vehicle's speed are presented in Figures 5 and 6.

As mentioned earlier, the injury risk was mostly dependent of the SV vehicle's speed. Based on the results shown in Figure 13, the MAIS 2+ injury risk was more than $40 \%$ for the vehicle speed higher than $150 \mathrm{kmph}$, whereas the injury risk decreased only by $6 \%$ if the initial distance (detection range) increases from $30 \mathrm{~m}$ to $125 \mathrm{~m}$. It must be noted that the injury risk was measured considering only the speed change parameter and other factors related to mitigation mechanisms (e.g., airbag and vehicle structure) were not considered. The crash deformation energy (vehicle damage) variation versus SV vehicle speed and types of algorithms are also plotted in Figure 13. The only study that we could find related to the effects of AEB systems on vehicle damage was by Doyle et al. [28]. They utilized the insurance claim data for specific vehicle models and pointed out that the AEB system can effectively reduce the vehicle's damage by $6 \%$ to $18 \%$. However, they did not include the factors such 

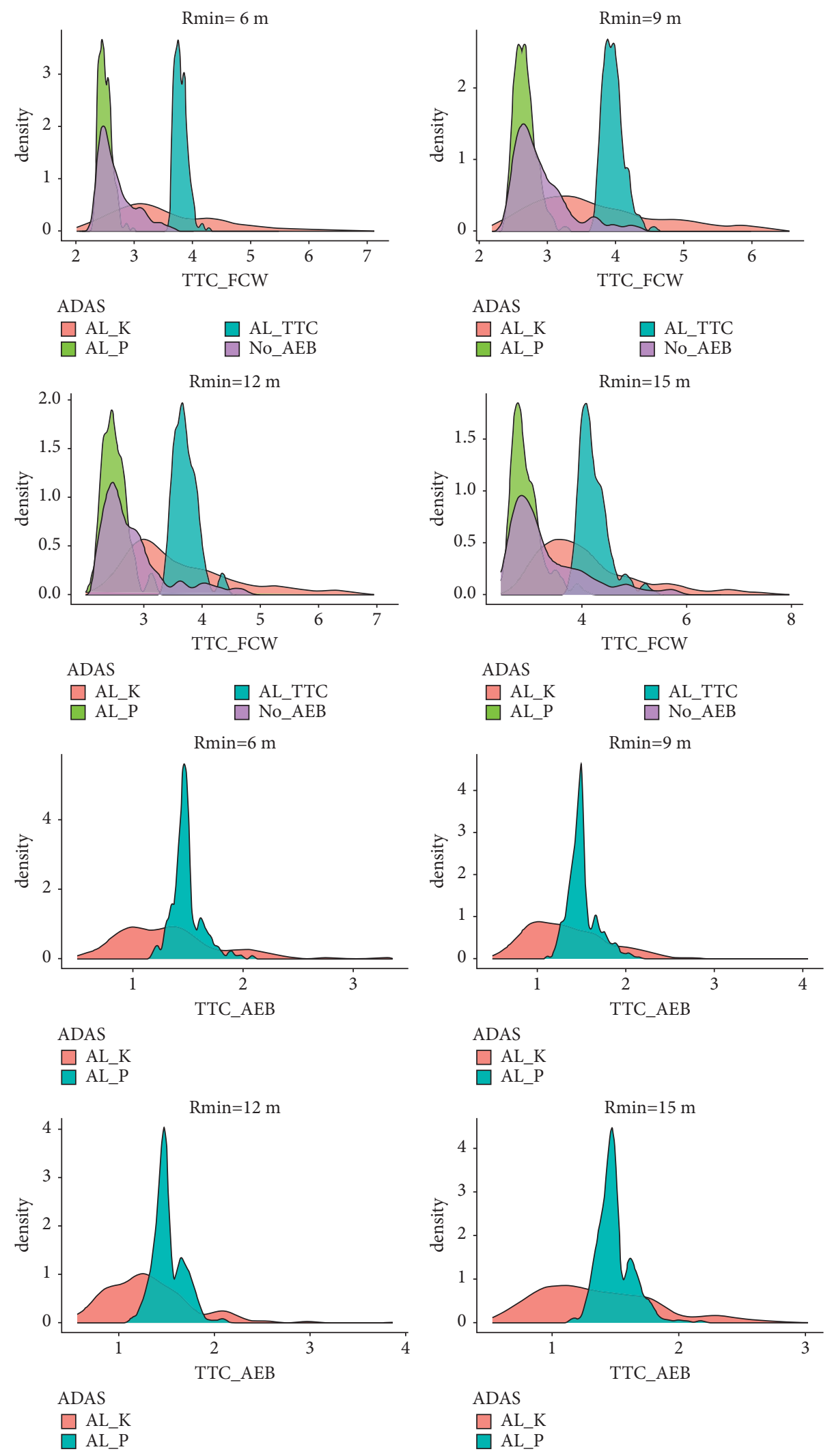

FIGURE 5: The kernel density estimate of the calculated TTC for FCW and AEB systems based on different safety margin $\left(R_{\text {min }}\right)$ values for different algorithms. (a) $R \min =6 \mathrm{~m}$. (b) $R \min =9 \mathrm{~m}$. (c) $R \min =12 \mathrm{~m}$. (d) $R_{\min }=15 \mathrm{~m}$. 


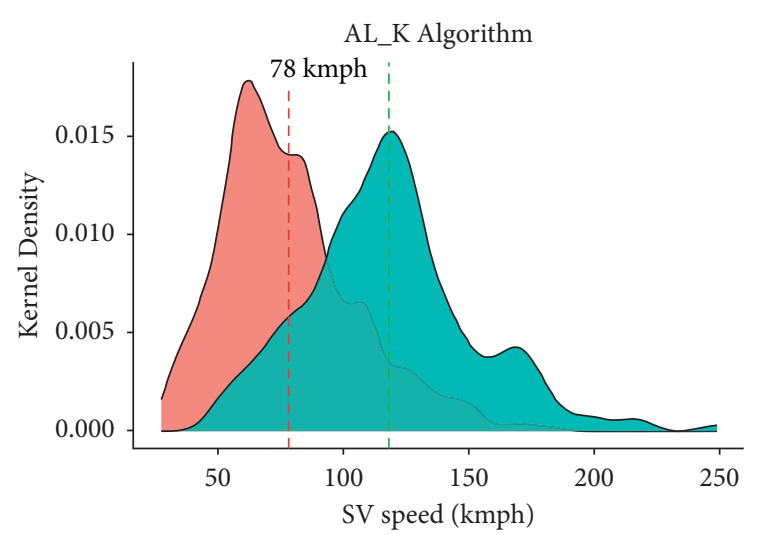

Crash

$\square 0$

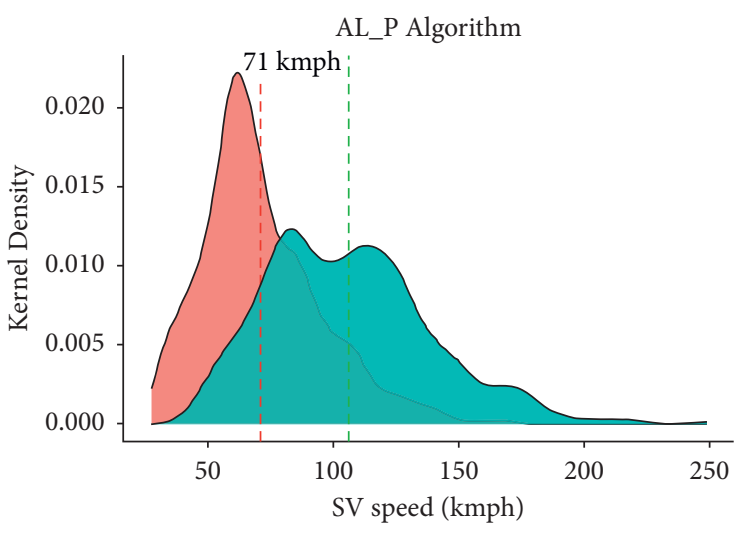

Crash

(a)

(b)

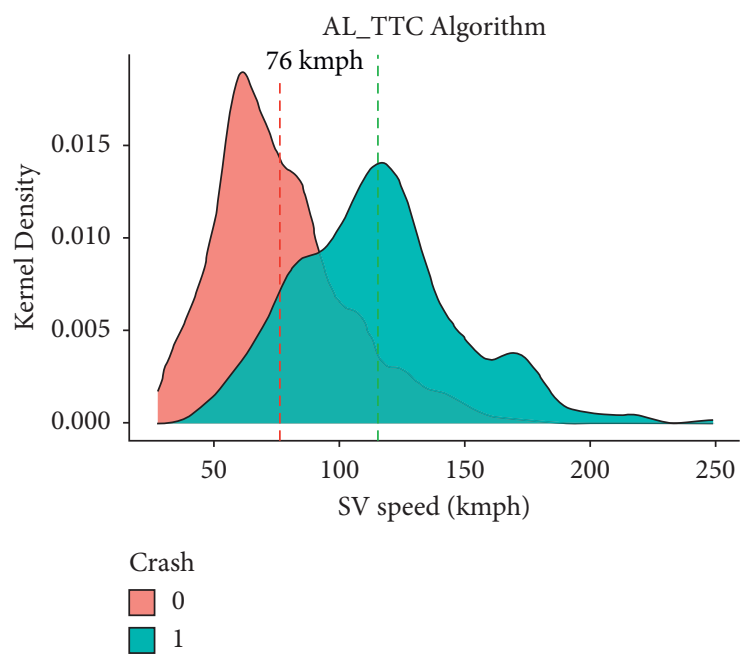

(c)

Figure 6: The kernel density estimate of subject vehicle's speed based on AEB activation for different algorithms (the effectiveness of different AEB algorithms based on subject vehicle's speed). (a) AL_K algorithm. (b) AL_P algorithm. (c) AL_TTC algorithm.

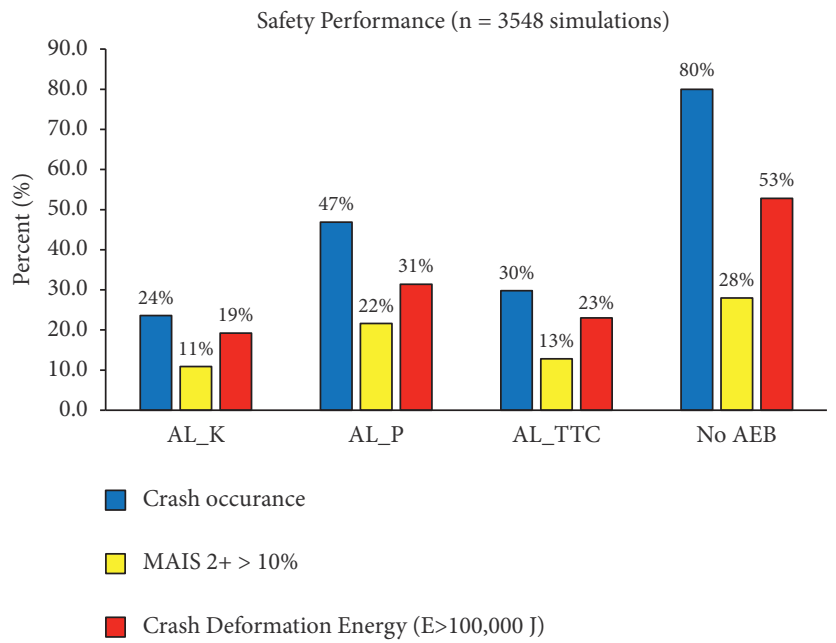

Figure 7: Measured safety performance based on the FCW/AEB type. 


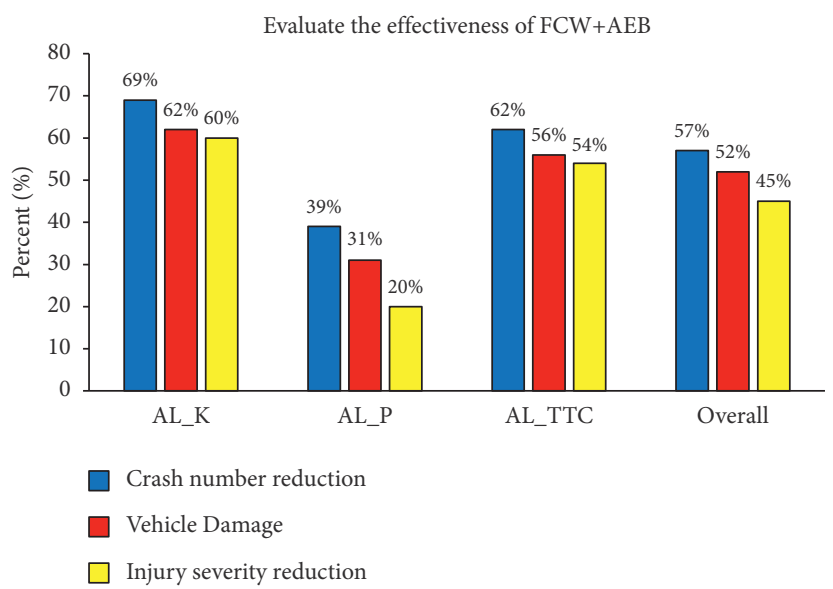

FIgURE 8: Summary of the estimated effectiveness of FCW + AEB in three aspects.

TABle 7: Regression analysis results: (a) crash model, (b) AEB model, (c) energy model, and (d) injury model.

\begin{tabular}{|c|c|c|c|c|c|c|c|c|c|c|c|c|}
\hline \multirow{2}{*}{ Regressors } & \multicolumn{3}{|c|}{ Crash model $^{1}$} & \multicolumn{3}{|c|}{ AEB model ${ }^{1}$} & \multicolumn{3}{|c|}{ Energy model $^{2}$} & \multicolumn{3}{|c|}{ Injury model $^{2}$} \\
\hline & $\beta$ & SE & Sig. flag & $\beta$ & SE & Sig. flag & $\beta$ & SE & Sig. flag & $\beta$ & $\mathrm{SE} \quad \mathrm{Si}$ & Sig. flag \\
\hline Intercept & -3.156 & 0.253 & $* * *$ & -3.435 & 0.340 & $* * *$ & -162420.49 & 10122.17 & $* * *$ & -12.373 & 1.500 & $* * *$ \\
\hline Detection range & -0.049 & 0.001 & $* * *$ & -0.029 & 0.001 & $* * *$ & -729.29 & 38.58 & $* * *$ & -0.073 & 0.006 & $* * *$ \\
\hline Driver reaction time & 2.651 & 0.082 & $* * *$ & 2.743 & 0.117 & $* * *$ & 44706.31 & 294 & $* * *$ & 3.737 & 0.436 & $* * *$ \\
\hline Safety & -0.096 & 0.008 & $* * *$ & -0.133 & 0.010 & $* * *$ & -1950.66 & & $* * *$ & -0.197 & 0.048 & $* * *$ \\
\hline Road friction & -0.163 & 0.296 & ns & 2.894 & 0.399 & $* * *$ & -595.93 & 1192 & ns & -2.399 & 1.768 & ns \\
\hline Br_inp1 & -1.463 & 0.063 & $* * *$ & 0.672 & 0.077 & $* * *$ & -35248.83 & 2437.02 & $* * *$ & -3.339 & 0.361 & $* * *$ \\
\hline Subject v & 0.065 & 0.001 & $* * *$ & 0.069 & 0.002 & $* * *$ & 4490.73 & 32.86 & $* * *$ & 0.409 & 0.005 & $* * *$ \\
\hline 's speed & -0.001 & 0.002 & Ns & 0.023 & 0.003 & $* * *$ & -1512.25 & 78. & $* * *$ & -0.133 & 0.011 & $* * *$ \\
\hline Br_L & 0.327 & 0.024 & $* * *$ & 0.318 & 0.032 & $* * *$ & 12438.63 & 923.16 & $* * *$ & 1.139 & 0.137 & $* * *$ \\
\hline ADASAL_P & 2.311 & 0.083 & $* * *$ & 2.003 & 0.104 & $* * *$ & 40057.07 & 3063.87 & $* * *$ & 6.365 & 0.454 & $* * *$ \\
\hline $\mathrm{ADAS}$ & 0.599 & 0.080 & $* * *$ & -0.571 & 0.077 & $* * *$ & 9267.35 & 3064.09 & $* * *$ & 0.714 & 0.454 & Ns \\
\hline \multirow[t]{2}{*}{ ADASNo_AEB } & 5.167 & 0.107 & $* * *$ & - & - & - & 106315.14 & 3063.87 & $* * *$ & 8.324 & 0.454 & $* * *$ \\
\hline & \multicolumn{3}{|c|}{$\begin{array}{c}\mathrm{n}: 14,185 ; \mathrm{df}: 14,174 \\
\quad R 2=0.556 ; p \approx 0\end{array}$} & \multicolumn{3}{|c|}{$\begin{array}{c}\mathrm{n}: 10,637 ; \mathrm{df}: 10,627 \\
\quad R 2=0.432 ; p \approx 0\end{array}$} & \multicolumn{3}{|c|}{$\begin{array}{l}\mathrm{n}: 14,185 ; \mathrm{df}: 14,174 \\
\quad R 2=0.605 ; p \approx 0\end{array}$} & \multicolumn{3}{|c|}{$\begin{array}{c}\mathrm{n}: 14,185 ; \mathrm{df}: 14,174 \\
R 2=0.366 ; p \approx 0\end{array}$} \\
\hline
\end{tabular}

Logistic regression modelMultiple linear regression model. Significance codes: $\mathrm{P} \leq 0.05:{ }^{*} ; p \leq 0.01:{ }^{* *} ; p \leq 0.001:{ }^{* * *} ; p>0.05: \mathrm{ns}$.

as vehicle speed and driver reaction in their statistical model. Considering these two factors, the results of the current study indicated that the type of AEB safety model can significantly change the crash deformation energy.

The injury risk depends on characteristics of the occupant (age, gender, position, etc.), vehicle's structure (body stiffness, seat mechanism, and passive safety systems), and the impact mechanism. However, in this study, we were only able to use the $\Delta V_{\mathrm{sv}}$, which depends on the impact parameters, to measure the MAIS 2+ injury risk. Therefore, the injury highly depends on vehicle body stiffness and restitution factor obtained for each reconstructed rear-end crash scenario. Figure 14 shows the injury risk curves based on crash deformation energy and speed of the subject vehicle for each crash scenario. For example, in the $\mathrm{C} 2$ scenario, the subject vehicle was the passenger car and the lead vehicle was a heavyduty truck. Hence, the subject vehicle's driver experienced a higher injury risk with respect to the vehicle's speed change because of the significant difference in vehicles' mass.

It is important to note that since the aim of this study was to find how the type of safety algorithms can change the rear- end crash outcomes, selecting other vehicle types would result in a similar relationship between parameters but with different intensities. For example, if instead of a pick-up truck we had a compact sedan as a subject vehicle, the amount of injury risk and crash deformation would have been higher at a certain speed range. However, we would have seen the same relationship between the type of ADAS system, vehicle speed, injury risk, and crash deformation.

The simulations were also categorized based on the SV vehicle's initial position into three ranges (see Figure 15). In $55 \%$ of simulations, the SV's initial distance was greater than the warning range. This is a typical situation for FCW/AEB systems which provides more time for the driver to react and decelerate the vehicle. The two other ranges were when the initial position was either between the warning and braking range or less than the braking range $(39 \%$ and $5 \%$ of cases, respectively). As mentioned earlier, these situations can happen in real-world road traffic conflicts due to the lane change or merging onto the roadway. The corresponded crash reduction based on initial distance was $33 \%, 45 \%$, and 95\% from high to short distance, respectively. This was 


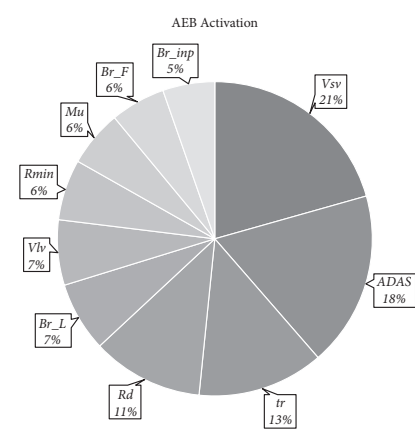

(a)

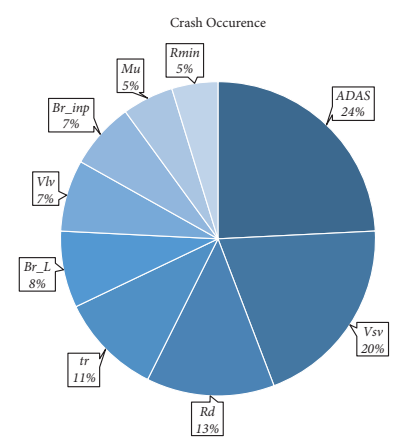

(b)

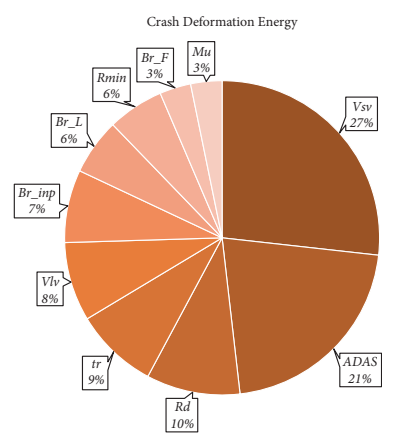

(c)

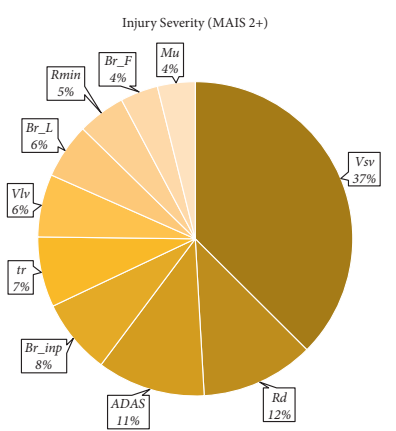

(d)

Figure 9: The results of parameter importance evaluation using Boruta model for each outcome. (a) AEB activation. (b) Crash occurrence. (c) Crash deformation energy. (d) Injury severity (MAIS 2+).
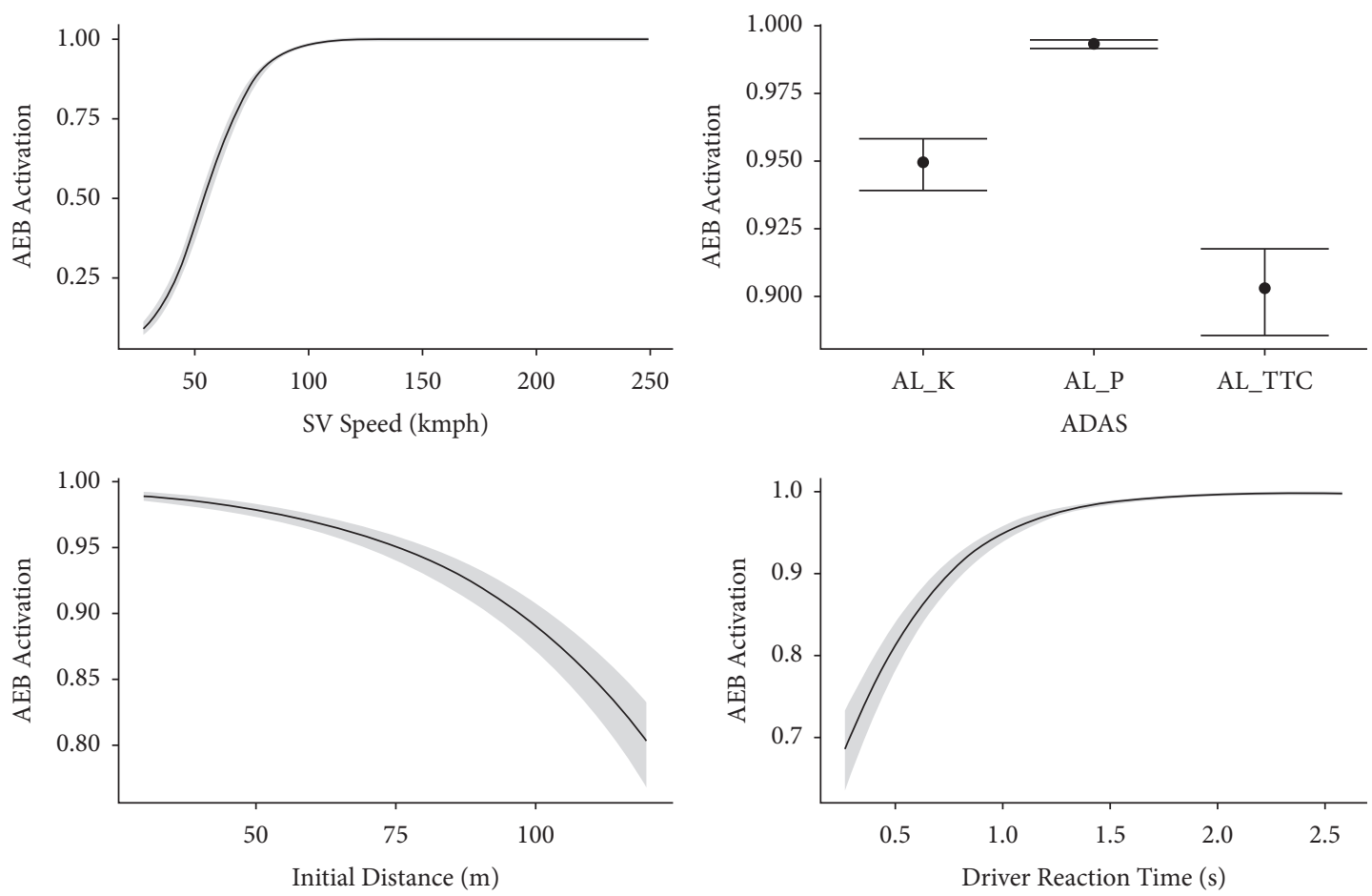

Figure 10: Effect plots for four important parameters resulted in the AEB activation model (confidence interval of 95\%).

expected because the rear-end crash is more likely in close distance car-following scenarios.

3.3. Limitations. This study has some limitations that should be mentioned. While the focus of this study was to evaluate the AEB system, some vehicles might have other collisionavoidance technologies, including the adaptive cruise control that could have affected the vehicle performance in carfollowing scenarios. It should be noted that the focus of the presented study was only on the algorithm, driver reaction, and road parameters and assumed that the detection systems are similar in all SV vehicles with the same value for sensor delay $(0.2 \mathrm{~s})$. The car-following scenarios analyzed in this study were on a straight road, whereas the FCW/AEB could potentially perform differently on a slope or curve road. This is still a challenging topic that needs to be addressed. [75].

Furthermore, the motion control systems such as a model predictive controller or a proportional-integral derivative can change the vehicle dynamic response too. Considering the related controller factors can bring more insight into how crash avoidance systems perform in different situations. The reconstruction technique that was used to measure the crash severity and speed change was limited by the available information from the NHTSA crash database, PC-Crash library information, and our optimization method. Therefore, the injury severity and vehicle damage resulting from these simulations may not be generalized to all types of vehicles because changing vehicle characteristics can result in different impact parameters. 

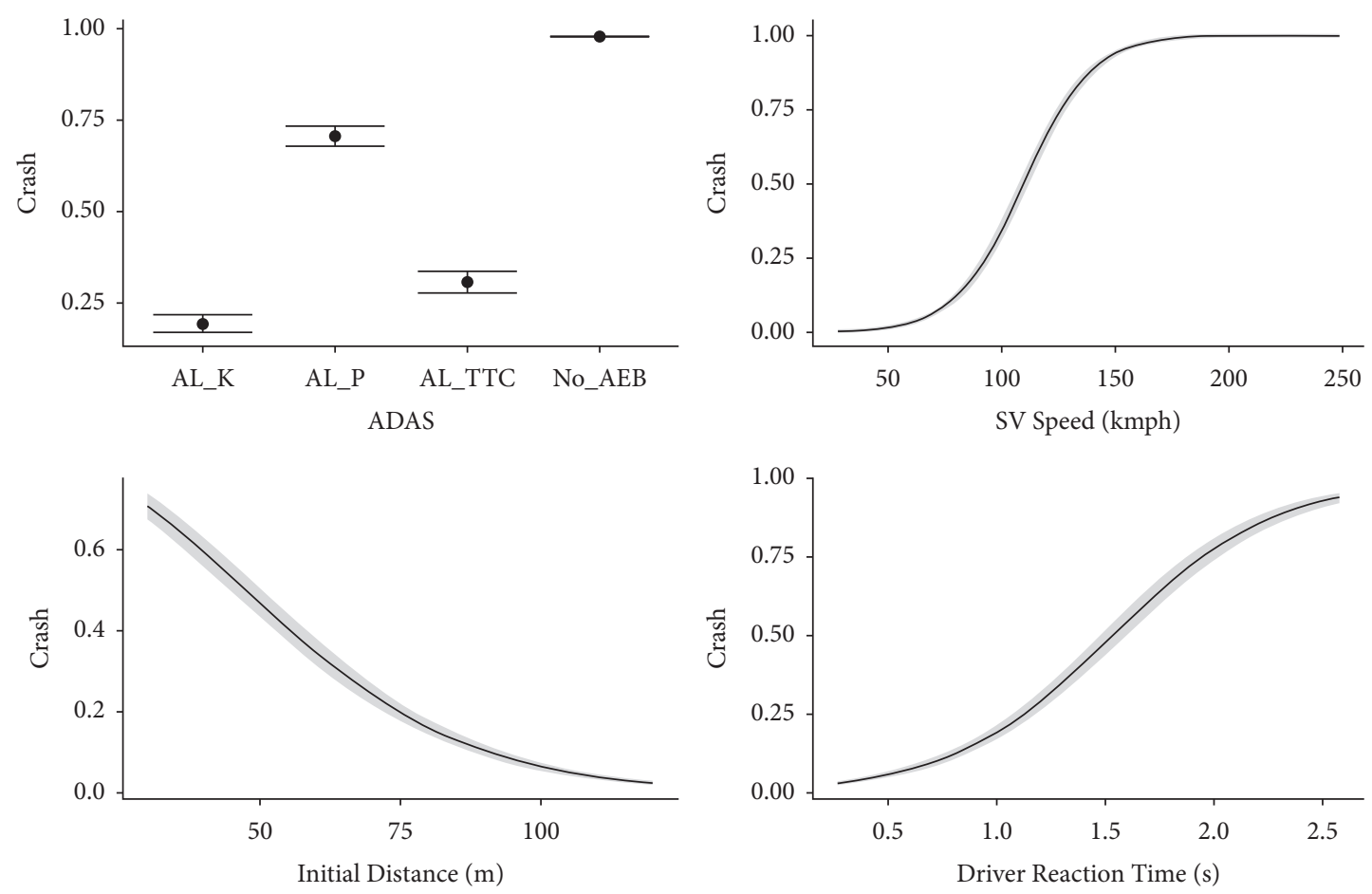

FIGURE 11: Effect plots for four important parameters resulted in the crash model (confidence interval of 95\%).

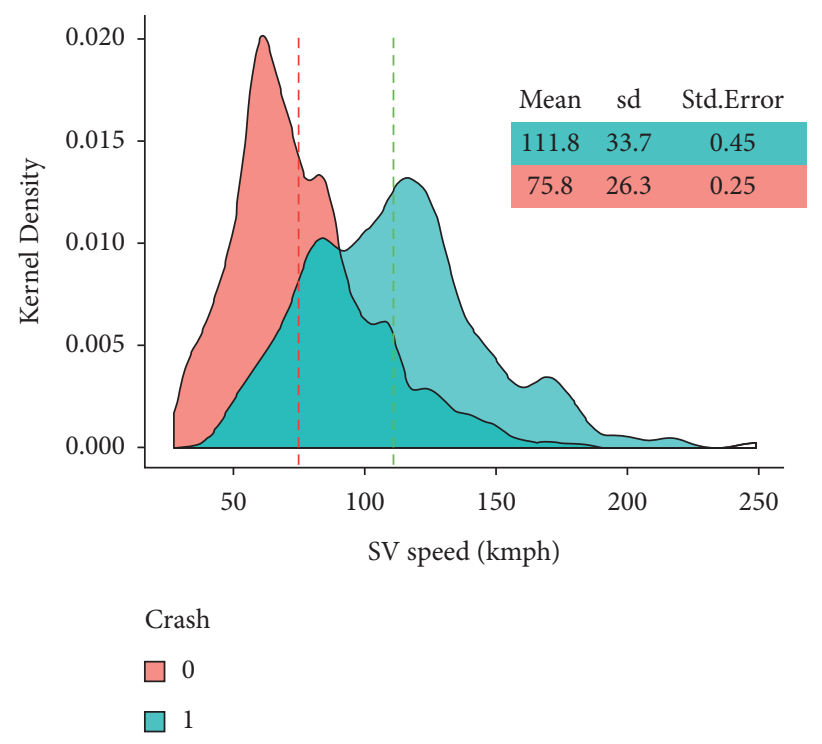

FIgURE 12: The kernel density estimate of SV vehicle's speed equipped with AEB system (no crash: 0; crash occurred: 1).

We also applied recursive feature elimination (RFE) methods and built a random forest model in the RFE algorithm to select the most important variables. However, the outputs obtained by this backward selection method revealed that all the variables had almost the same level of importance due to their distribution which made no sense in terms of interpretation. Hence, we decided to apply a more efficient variable selection method (Boruta) to rank predictors based on their predictive power and adjust for many interactions of control variables. Last but not least, the falsepositive cases for AEB activation were not considered in this study which could affect the driver decision-making process. 

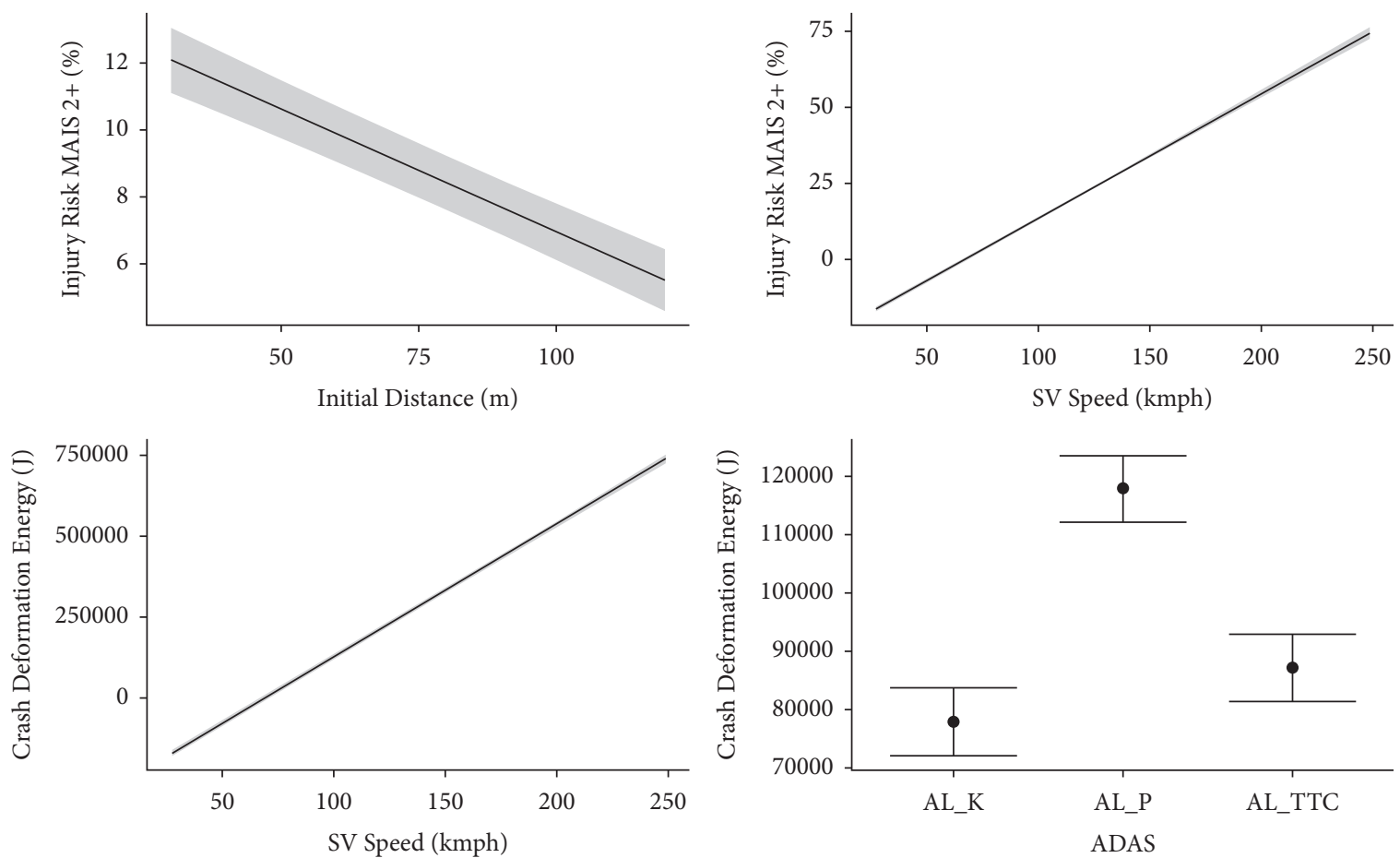

FiguRE 13: Effect plots for two important parameters resulted in the energy and injury models (confidence interval of 95\%).

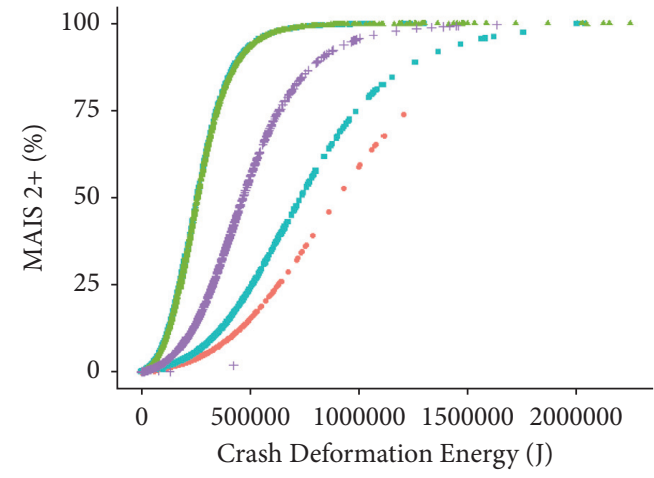

Scenario

- $\mathrm{C} 1$

$\triangle \mathrm{C} 2$

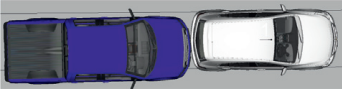

C1: Pickup Truck

Compact Passenger Car
$\mathrm{C} 3$

$+\mathrm{C} 4$

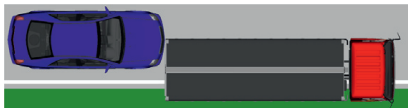

C2: Sedan Passenger Car

Heavy Duty Truck

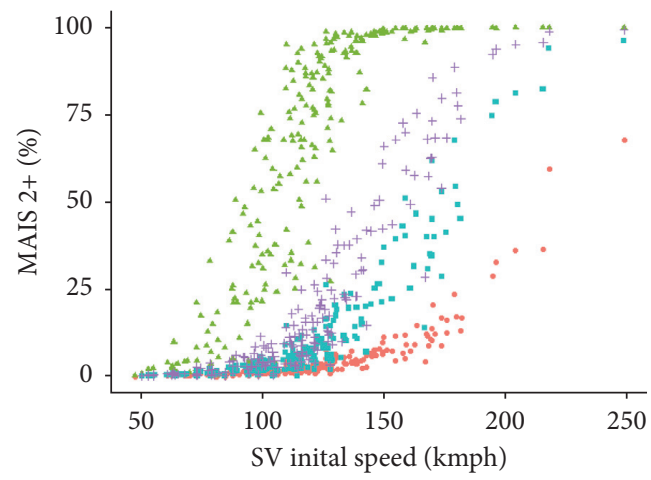

Scenario

$-\mathrm{C} 1=\mathrm{C} 3$

$\triangle \mathrm{C} 2+\mathrm{C} 4$

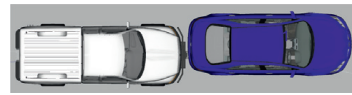

C3: Pickup Truck Sedan Passenger Car

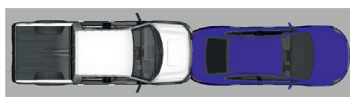

C4: Pickup Truck Sedan Passenger Car

Figure 14: The risk of injury based on the crash deformation energy and speed for each crash scenario.
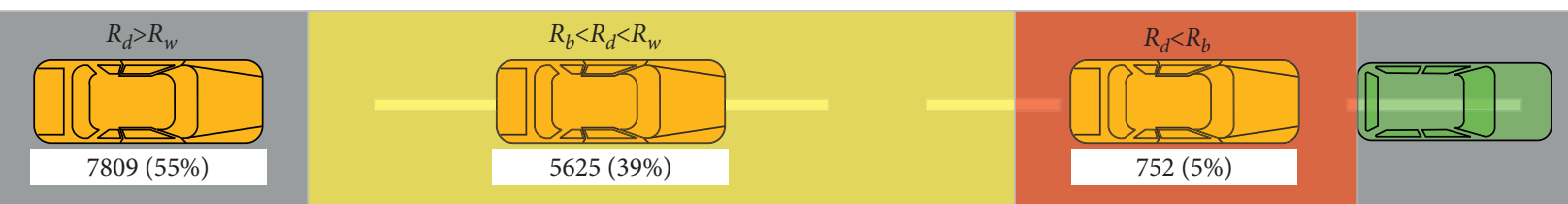

FIGURE 15: The number of simulations based on SV's initial position and corresponding crash number. 


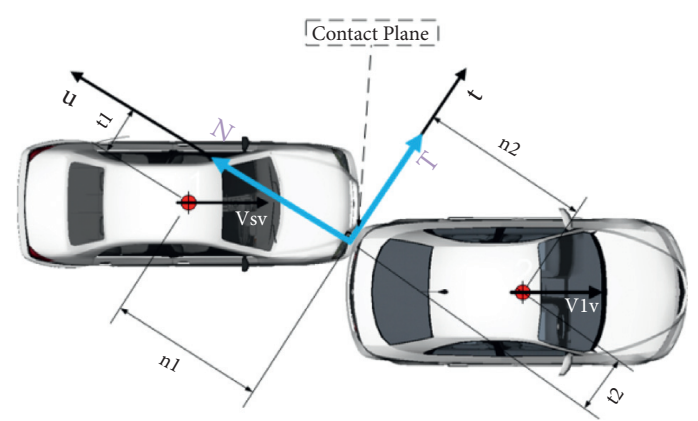

FIgURE 16: The impact configuration in PC-Crash.

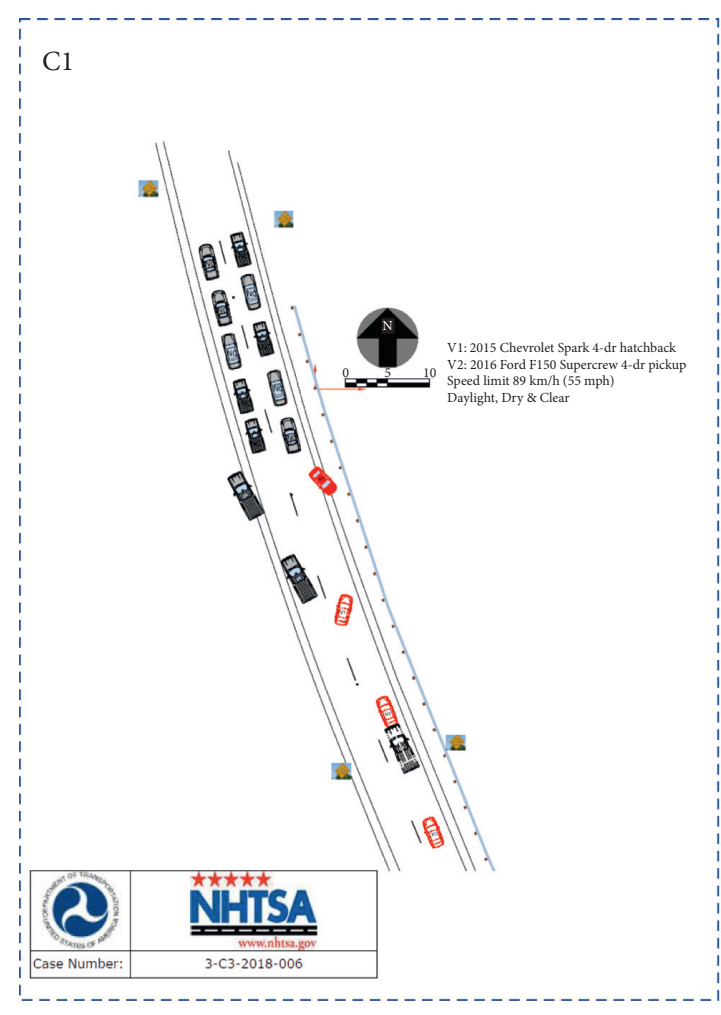

(a)

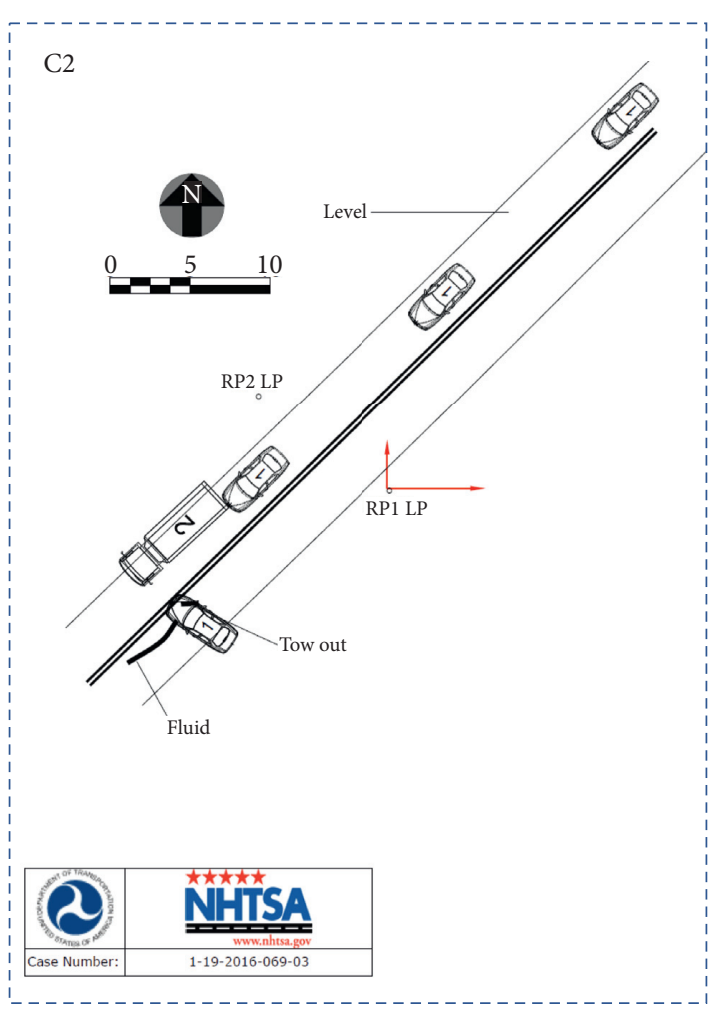

(b)

Figure 17: Continued. 


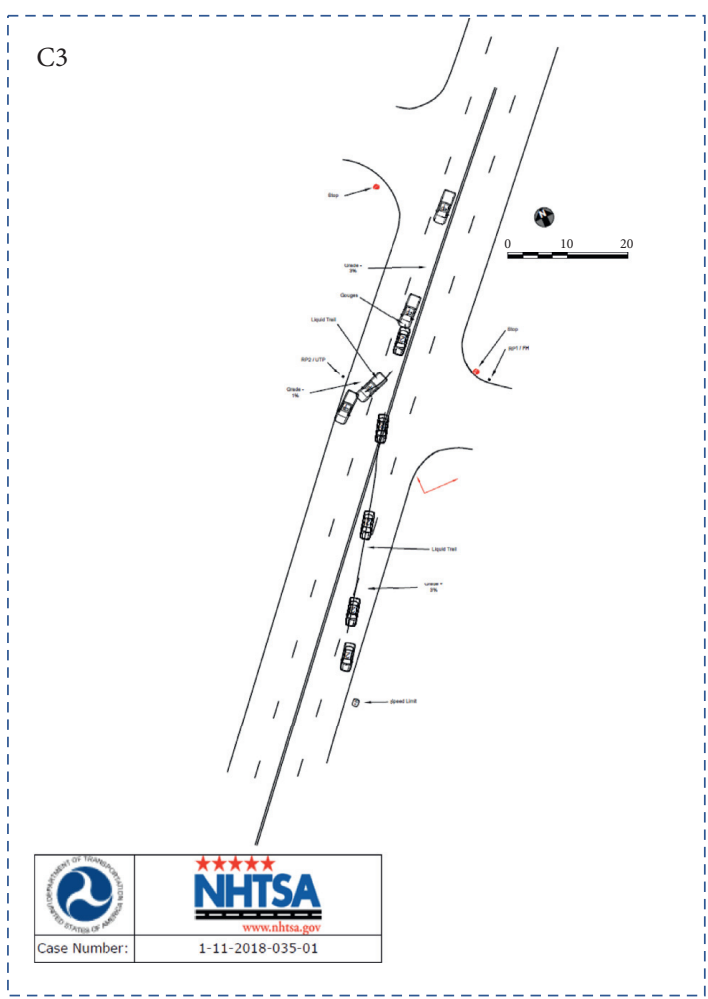

(c)

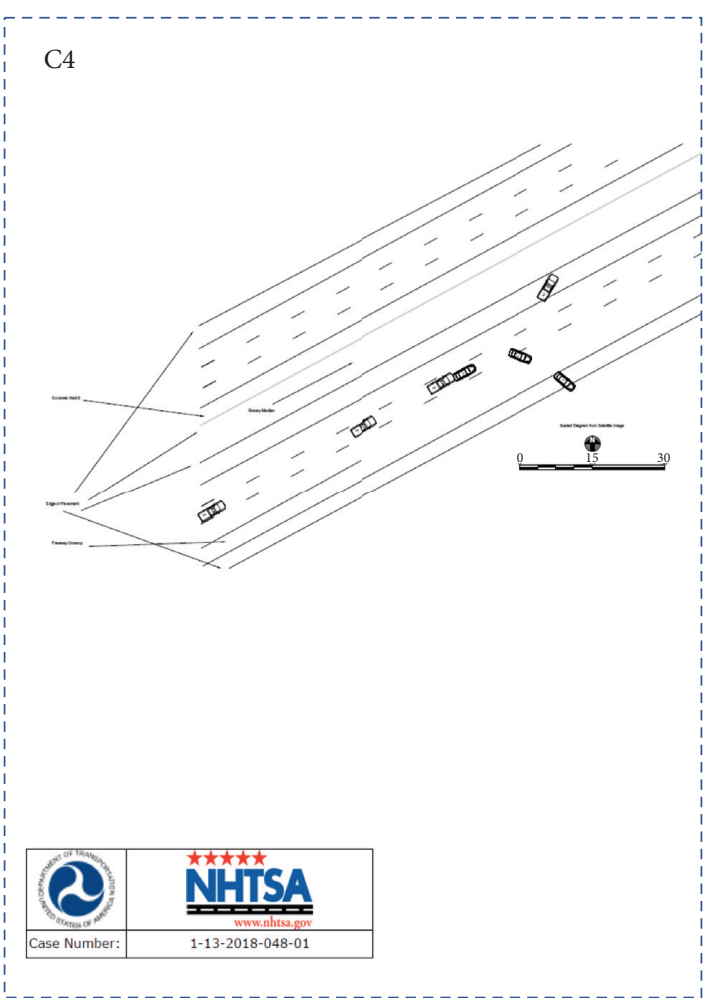

(d)

Figure 17: Crash scene diagram for each scenario. (a) C1. (b) C2. (c) C3. (d) C4.

TABLE 8: Summary of parameters resulted from the crash reconstruction.

\begin{tabular}{lcccc}
\hline \multirow{2}{*}{ Impact parameter } & \multicolumn{4}{c}{ Crash reconstruction case } \\
& $\mathrm{C} 1$ (pick-up truck) & $\mathrm{C} 2$ (4-door sedan) & C3 (pick-up truck) & C4 (pick-up truck) \\
\hline Restitution factor & 0.1 & 0.12 & 0.11 & 0.12 \\
Contact friction & 0.67 & 0.6 & 0.55 & 0.63 \\
Body stiffness $(\mathrm{N} / \mathrm{m})$ & 382590 & 145678 & 422811 & 325299 \\
\hline
\end{tabular}

TABLE 9: Summary of SV vehicle parameters that were used in accident reconstruction*.

\begin{tabular}{|c|c|c|c|c|}
\hline \multirow{2}{*}{ Vehicle parameter } & \multicolumn{4}{|c|}{ Crash reconstruction case } \\
\hline & $\mathrm{C} 1$ (pick-up truck) & C2 (4-door sedan) & C3 (pick-up truck) & C4 (pick-up truck) \\
\hline$\overline{\mathrm{L} / \mathrm{W} / \mathrm{H}(\mathrm{m})}$ & $4.6 / 2 / 2.2$ & $4.6 / 1.8 / 1.4$ & $5 / 1.9 / 1.8$ & $5.5 / 2.2 / 2.8$ \\
\hline $\begin{array}{l}\text { Inertial properties } \\
\text { yaw/roll/pitch }\left(\mathrm{kg} \cdot \mathrm{m}^{2}\right)\end{array}$ & $4099 / 1261 / 4099$ & $2439 / 731 / 2439$ & $4219 / 1265 / 4219$ & $4947 / 1341 / 4947$ \\
\hline Tire model & $\begin{array}{l}\text { Linear with maximum } \\
\text { lateral slip of } 10^{\circ}\end{array}$ & $\begin{array}{l}\text { Linear with maximum } \\
\text { lateral slip of } 10^{\circ}\end{array}$ & $\begin{array}{l}\text { Linear with maximum } \\
\text { lateral slip of } 10^{\circ}\end{array}$ & $\begin{array}{l}\text { Linear with maximum } \\
\text { lateral slip of } 10^{\circ}\end{array}$ \\
\hline Tire size front/rear & 285/35 R19 & 255/35 R18 & 265/60 R 18 & $235 / 40 \mathrm{R} 17$ \\
\hline $\begin{array}{l}\text { Suspension properties } \\
\text { (stiffness/damping) }\end{array}$ & $\begin{array}{c}31882(\mathrm{~N} / \mathrm{m}) / 3586 \\
(\mathrm{Ns} / \mathrm{m})\end{array}$ & $24179(\mathrm{~N} / \mathrm{m}) / 2731(\mathrm{Ns} / \mathrm{m})$ & $35234(\mathrm{~N} / \mathrm{m}) / 3963(\mathrm{Ns} / \mathrm{m})$ & $34860(\mathrm{~N} / \mathrm{m}) / 3921(\mathrm{Ns} / \mathrm{m})$ \\
\hline Wheelbase & 2.85 & 2.75 & 3 & 3 \\
\hline
\end{tabular}

${ }^{*}$ These values have been extracted from the PC-Crash library and available public domain information. 


\section{Summary and Conclusion}

Efforts have been made in this study to provide some insights into the effectiveness of different AEB decision-making algorithms on rear-end crash outcomes. The real-world rear-end crash scenarios were simulated for a wide range of parameters that were extracted from either real-world crash data or literature. The driver input was also modeled using the reaction time and brake exertion. Three architects of FCW + AEB algorithms were selected to analyze their effect on vehicle performance to avoid or mitigate the crash using the following metrics: the crash occurrence rate, injury risk, and crash deformation energy. Using a series of simulation results, the statistical model was used to evaluate the relationship between those metrics and input variables, and the importance of parameters was measured based on the Boruta algorithm.

The overall effectiveness assessment of the AEB system has shown a $57 \%$ reduction of rear-end crashes, a $52 \%$ reduction of injury severity (striking vehicle's passengers), and a $47 \%$ reduction of damages for striking vehicles. The results also indicated that the available AEB algorithms are more effective up to the average speed of $80 \mathrm{kmph}$. The results of the Boruta model indicated that the speed of the subject vehicle, type of AEB algorithm, sensor detection range (initial distance), and driver reaction time are the most important parameters on crash outcomes and activation of AEB systems. In addition, the results indicated that the performance of FCW had a direct impact on the effectiveness of the AEB system for the integrated FCW + AEB system. This is important for developing the partial brake systems (before full brake exertion) that are recently under development for the vehicles to replace the driver brake reaction [43]. These technologies are expected to play a key role in the future of transportation, particularly in the transition period from conventional vehicles to fully autonomous vehicles.

This study also provides basic information to identify some edge case scenarios that can be used for the safety evaluation of these systems at different stages of development and deployment. In the future, we plan to study the effectiveness of AEB algorithms that are based on vehicle-tovehicle connection or developed for level four of autonomous vehicles.

\section{Appendix}

\section{A. PC-Crash Simulation}

The PC-Crash simulation has two main parts: modeling the trajectory of the vehicle: the kinetics model which considers all vehicle dynamic forces in three directions was used in PCCrash simulations.

Impact model: the impact model was based on combined conservation of linear and rotational momentum in three directions with restitution factor. Using the coefficient of restitution allows us to have a more realistic assessment of the impact phase by dividing it into the deformation and restoration phase. This reflects the capacity of the contacting bodies to recover from the impact. For simplicity, the $2 \mathrm{D}$ impact model is presented in Figure 16, whereas in PCCrash, the 3D analysis is conducted.

The following equations show how the postcrash velocity (only for SV) is measured:

$$
\begin{aligned}
& V_{s v_{t}}=V_{s v_{T}}+\omega_{s v_{z}} \times t_{1}, \\
& V_{s v_{n}}=V_{s v_{N}}-\omega_{s v_{z}} \times n_{1},
\end{aligned}
$$

where $V_{\text {Sv_T }}$ and $V_{\text {sv_N }}$ are the tangential and normal velocity components of SV center of gravity, $\omega_{s v_{z}}$ is the yaw speed, and $t_{1}$ and $n_{1}$ are the distances of the center of gravity to the impulse point. The components of the relative speed between two vehicles at the impulse point with assuming the $V_{l v_{t}}$ and $V_{l v_{n}}$ are the velocity components of LV as shown in Figure 17,

$$
\begin{aligned}
V_{t} & =V_{s v_{t}}-V_{l v_{t}}, \\
V_{n} & =V_{s v_{n}}-V_{l v_{n}} .
\end{aligned}
$$

Also, the conservation of linear and rotational momentum for SV vehicle is

$$
\begin{aligned}
m_{s v}\left(V_{s_{v t}}^{\prime}-V_{s v_{t}}\right) & =T, \\
m_{s v}\left(V_{s_{v n}}^{\prime}-V_{s v_{n}}\right) & =N, \\
I_{s v_{z}}\left(\omega_{s_{v z}}^{\prime}-\omega_{s v_{z}}\right) & =-T n_{1}+N t_{1},
\end{aligned}
$$

where using the combination of the above equations enables us to measure the change of relative velocity which can be calculated from

$$
\begin{aligned}
V_{t}^{\prime} & =V_{t}+c_{1} T-c_{3} N, \\
V_{n}^{\prime} & =V_{n}-c_{3} T+c_{2} N,
\end{aligned}
$$

where

$$
\begin{aligned}
& c_{1}=\frac{1}{m_{1}}+\frac{1}{m_{2}}+\frac{n_{1}^{2}}{I_{s v_{z}}}+\frac{n_{2}^{2}}{I_{l v_{z}}}, \\
& c_{2}=\frac{1}{m_{1}}+\frac{1}{m_{2}}+\frac{t_{1}^{2}}{I_{s v_{z}}}+\frac{t_{2}^{2}}{I_{l v_{z}}}, \\
& c_{3}=\frac{n_{1} t_{2}}{I_{s v_{z}}}+\frac{n_{2} t_{2}}{I_{l v_{z}}} .
\end{aligned}
$$

Depending on the restitution factor and contact friction, the above equations are solved to calculate the postimpact speed. PC-Crash has built-in functions that if the two vehicles made contact during the simulation, the impact characteristics including crash deformation energy are calculated from the contact point based on the body's stiffness, restitution factor, and contact friction. This energy is measured using the following equation [56]:

$$
E=\frac{F}{2} \times s_{\text {def }},
$$

where $E$ is the deformation energy, $\mathrm{F}$ is the impact force, and $s_{\text {def }}$ is the crush depth and depends on body stiffness. The optimum values of impact parameters resulted from four crash reconstruction simulations for the following vehicle are presented in Table 8. It shows that the restitution factor and 
contact friction were very close regardless of the type of vehicle. However, the body stiffness which determines the crush depth was significantly different. For example, the pick-up truck had almost two times a stiffer body than a passenger car.

General vehicle information regarding the subject vehicle is presented in Table 9.

\section{Data Availability}

The datasets generated during the current study are available in the GitHub repository: https://github.com/CIALReza/ AEB-FCW-Simulation-Data.

\section{Conflicts of Interest}

The authors declare that they have no conflicts of interest or personal relationships that could have appeared to influence the work reported in this paper.

\section{References}

[1] E. Donges, "A conceptual framework for active safety in road traffic," Vehicle System Dynamics, vol. 32, no. 2-3, pp. 113-128, 1999.

[2] R. Mohebbi, R. Gray, and H. Z. Tan, "Driver reaction time to tactile and auditory rear-end collision warnings while talking on a cell phone," Human Factors: The Journal of the Human Factors and Ergonomics Society, vol. 51, no. 1, pp. 102-110, 2009.

[3] The Use of Forward Collision Avoidance Systems to Prevent and Mitigate Rear-End Crashes, National Transportation Safety Board, Washington, DC, 2015.

[4] U. Sander and N. Lubbe, "Market penetration of intersection AEB: characterizing avoided and residual straight crossing path accidents," Accident Analysis \& Prevention, vol. 115, pp. 178-188, 2018.

[5] J. S. Jermakian, "Crash avoidance potential of four passenger vehicle technologies," Accident Analysis \& Prevention, vol. 43, no. 3, pp. 732-740, 2011.

[6] X. Zhao, S. Jing, F. Hui, R. Liu, and A. J. Khattak, "DSRCbased rear-end collision warning system - an error-component safety distance model and field test," Transportation Research Part C: Emerging Technologies, vol. 107, pp. 92-104, 2019.

[7] K. Lee and H. Peng, "Evaluation of automotive forward collision warning and collision avoidance algorithms," Vehicle System Dynamics, vol. 43, no. 10, pp. 735-751, 2005.

[8] T. L. Brown, J. D. Lee, and D. V. McGehee, "Human performance models and rear-end collision avoidance algorithms," Human Factors: The Journal of the Human Factors and Ergonomics Society, vol. 43, no. 3, pp. 462-482, 2001.

[9] J. D. Lee, D. V. McGehee, T. L. Brown, and M. L. Reyes, "Collision warning timing, driver distraction, and driver response to imminent rear-end collisions in a high-fidelity driving simulator," Human Factors: The Journal of the Human Factors and Ergonomics Society, vol. 44, no. 2, pp. 314-334, 2002.

[10] R. Ervin et al., Automotive Collision Avoidance System Field Operational Test Report: Methodology and Results, NHTSA, Washington, D.C., 2005.

[11] Y. Sugimoto and C. Sauer, "Effectiveness estimation method for advanced driver assistance system and its application to collision mitigation brake system," in Proceedings of the 19th
International Technical Conference on the Enhanced Safety of Vehicles, ESV), Washington D.C, June 2005.

[12] W. Najm et al., Evaluation of an Automotive Rear-End Collision Avoidance System, Department of Transportation, United States, 2006.

[13] J. J. Breuer et al., "Real world safety benefits of brake assistance systems," in Proceedings of the 20th International Technical Conference on the Enhanced Safety of Vehicles, ESV), Lyon, France, June 2007.

[14] A. H. Jamson, F. C. H. Lai, and O. M. J. Carsten, "Potential benefits of an adaptive forward collision warning system," Transportation Research Part C: Emerging Technologies, vol. 16, no. 4, pp. 471-484, 2008.

[15] A. Kullgren, "Dose-response models and EDR data for assessment of injury risk and effectiveness of safety systems," in Proceedings of the IRCOBI Conference, ESV, Bern, Switzerland, 2008.

[16] A. Georgi et al., "New approach of accident benefit analysis for rear end collision avoidance and mitigation systems," in Proceedings of the 21st International Technical Conference on the Enhanced Safety of Vehicles, ESV, Washington, D.C., April 2009.

[17] M. Kuehn, T. Hummel, and J. Bende, "Benefit estimation of advanced driver assistance systems for cars derived from reallife accidents," in Proceedings of the 21st International Technical Conference on the Enhanced Safety of Vehicles, ESV, Washington, D.C., April 2009.

[18] E. Coelingh, A. Eidehall, and M. Bengtsson, "Collision warning with full auto brake and pedestrian detection-a practical example of automatic emergency braking," in Proceedings of the 13th International IEEE Conference on Intelligent Transportation Systems, IEEE, Funchal, Portugal, September 2010.

[19] K. D. Kusano and H. C. Gabler, "Potential occupant injury reduction in pre-crash system equipped vehicles in the striking vehicle of rear-end crashes," in Proceedings of the Annals of Advances in Automotive Medicine/Annual Scientific Conference, NCBI, Bethesda MD, USA, January 2010.

[20] F. Bella and R. Russo, "A Collision Warning System for rearend collision: a driving simulator study," Procedia-Social and Behavioral Sciences, vol. 20, pp. 676-686, 2011.

[21] K. D. Kusano and H. Gabler, "Method for estimating time to collision at braking in real-world, lead vehicle stopped rearend crashes for use in pre-crash system design," SAE International Journal of Passenger Cars-Mechanical Systems, vol. 4, no. 2011, pp. 435-443, 2011.

[22] K. D. Kusano and H. C. Gabler, "Safety benefits of forward collision warning, brake assist, and autonomous braking systems in rear-end collisions," IEEE Transactions on Intelligent Transportation Systems, vol. 13, no. 4, pp. 1546-1555, 2012.

[23] I. Isaksson-Hellman and M. Lindman, "The effect of a lowspeed automatic brake system estimated from real life data," in Proceedings of the Annals of Advances in Automotive Medicine/Annual Scientific Conference, NCBI, Bethesda MD, USA, June 2012.

[24] R. Anderson et al., "Potential benefits of autonomous emergency braking based on in-depth crash reconstruction and simulation," in Proceedings of the 23rd International Conference on Enhanced Safety of Vehicles, ESV, Seoul, Republic of Korea, June 2013.

[25] C. Chauvel et al., "Automatic emergency braking for pedestrians effective target population and expected safety benefits," in Proceedings of the 23rd international technical 
conference on the enhanced safety of vehicles, ESV, Seoul, South Korea, May 2013.

[26] E. Rosen, "Autonomous emergency braking for vulnerable road users," in Proceedings of the IRCOBI Conference, Gothenburg (Sweden), September 2013.

[27] M. Rizzi, A. Kullgren, and C. Tingvall, "Injury crash reduction of low-speed Autonomous Emergency Braking (AEB) on passenger cars," in Proceedings of the IRCOBI Conference on Biomechanics of Impacts, IRCOBI, Berlin (Germany), September 2014.

[28] M. Doyle, A. Edwards, and M. Avery, AEB Real World Validation Using UK Motor Insurance Claims DataESV Conference, Eindhoven, Netherlands, 2015.

[29] B. Fildes, M. Keall, N. Bos et al., "Effectiveness of low speed autonomous emergency braking in real-world rear-end crashes," Accident Analysis \& Prevention, vol. 81, pp. 24-29, 2015.

[30] C. Flannagan et al., Large-scale Field Test of Forward Collision Alert and Lane Departure Warning Systems, NHTSA, Washington, D.C., 2016.

[31] K. Grove et al., Field Study of Heavy-Vehicle Crash Avoidance Systems, SAE International, Rosemont illinois, 2016.

[32] J. Han, O. Heo, M. Park, S. Kee, and M. Sunwoo, "Vehicle distance estimation using a mono-camera for FCW/AEB systems," International Journal of Automotive Technology, vol. 17, no. 3, pp. 483-491, 2016.

[33] I. Isaksson-Hellman and M. Lindman, "Evaluation of the crash mitigation effect of low-speed automated emergency braking systems based on insurance claims data," Traffic Injury Prevention, vol. 17, no. 1, pp. 42-47, 2016.

[34] A. L. Rosado et al., "Certainty and critical speed for decision making in tests of pedestrian automatic emergency braking systems," IEEE Transactions on Intelligent Transportation Systems, vol. 18, no. 6, pp. 1358-1370, 2016.

[35] X. Wang, M. Chen, M. Zhu, and P. Tremont, "Development of a kinematic-based forward collision warning algorithm using an advanced driving simulator," IEEE Transactions on Intelligent Transportation Systems, vol. 17, no. 9, pp. 2583-2591, 2016.

[36] J. B. Cicchino, "Effectiveness of forward collision warning and autonomous emergency braking systems in reducing front-torear crash rates," Accident Analysis \& Prevention, vol. 99, pp. 142-152, 2017.

[37] Y. Li, L. Xing, W. Wang, H. Wang, C. Dong, and S. Liu, "Evaluating impacts of different longitudinal driver assistance systems on reducing multi-vehicle rear-end crashes during small-scale inclement weather," Accident Analysis \& Prevention, vol. 107, pp. 63-76, 2017.

[38] N. Lubbe, "Brake reactions of distracted drivers to pedestrian Forward Collision Warning systems," Journal of Safety Research, vol. 61, pp. 23-32, 2017.

[39] J. M. Scanlon, R. Sherony, and H. C. Gabler, "Injury mitigation estimates for an intersection driver assistance system in straight crossing path crashes in the United States," Traffic Injury Prevention, vol. 18, no. 1, pp. S9-S17, 2017.

[40] J. S. Jermakian, S. Bao, M. L. Buonarosa, J. R. Sayer, and C. M. Farmer, "Effects of an integrated collision warning system on teenage driver behavior," Journal of Safety Research, vol. 61, pp. 65-75, 2017.

[41] C. A. Flannagan et al., Field Study of Light-Vehicle Crash Avoidance Systems: Automatic Emergency Braking and Dynamic Brake Support, Department of Transportation, United States, 2018.
[42] U. Sander and N. Lubbe, "The potential of clustering methods to define intersection test scenarios: assessing real-life performance of AEB," Accident Analysis \& Prevention, vol. 113, pp. 1-11, 2018.

[43] W. Wang, J. Xi, and D. Zhao, "Learning and inferring a driver's braking action in car-following scenarios," IEEE Transactions on Vehicular Technology, vol. 67, no. 5, pp. 3887-3899, 2018.

[44] L. Yue, M. Abdel-Aty, Y. Wu, and L. Wang, "Assessment of the safety benefits of vehicles' advanced driver assistance, connectivity and low level automation systems," Accident Analysis \& Prevention, vol. 117, pp. 55-64, 2018.

[45] Y. Wu, M. Abdel-Aty, J. Park, and J. Zhu, "Effects of crash warning systems on rear-end crash avoidance behavior under fog conditions," Transportation Research Part C: Emerging Technologies, vol. 95, pp. 481-492, 2018.

[46] S. Lee, E. Jeong, C. Oh, and G. Lee, "Estimation of the safety benefits of AEBS based on an analysis of the KIDAS database," KSCE Journal of Civil Engineering, vol. 23, no. 12, pp. 52085214, 2019.

[47] Y. Zhao, D. Ito, and K. Mizuno, "AEB effectiveness evaluation based on car-to-cyclist accident reconstructions using video of drive recorder," Traffic Injury Prevention, vol. 20, no. 1, pp. 100-106, 2019.

[48] N. Arbabzadeh, M. Jafari, M. Jalayer, S. Jiang, and M. Kharbeche, "A hybrid approach for identifying factors affecting driver reaction time using naturalistic driving data," Transportation Research Part C: Emerging Technologies, vol. 100, pp. 107-124, 2019.

[49] C. A. Flannagan and A. Leslie, Crash Avoidance Technology Evaluation Using Real-World Crash Data, Department of Transportation, United States, 2020.

[50] Z. Lei and S. Qin, "Research on forward collision warning system and fuzzy control of automatic emergency braking system," SAE International, 2020.

[51] S. Newstead, L. Budd, and A. Stephens, The Potential Benefits of Autonomous Emergency Braking Systems in Australia, Monash University, Melbourne Vic Australia, 2020.

[52] M. K. Salaani, D. Elsasser, and C. Boday, NHTSA's 2018 Heavy Vehicle Automatic Emergency Braking Test Track Research Results, SAE International, Rosemont illinois, 2020.

[53] L. Wang, H Zhong, W Ma, M Abdel-Aty, and J Park, "How many crashes can connected vehicle and automated vehicle technologies prevent: a meta-analysis," Accident Analysis \& Prevention, vol. 136, p. 105299, Article ID 105299, 2020.

[54] M. Zhu, X. Wang, and J. Hu, "Impact on car following behavior of a forward collision warning system with headway monitoring," Transportation Research Part C: Emerging Technologies, vol. 111, pp. 226-244, 2020.

[55] J. Kovaceva, A Bálint, R Schindler, and A Schneider, "Safety benefit assessment of autonomous emergency braking and steering systems for the protection of cyclists and pedestrians based on a combination of computer simulation and realworld test results," Accident Analysis \& Prevention, vol. 136, p. 105352, Article ID 105352, 2020.

[56] S. Datentechnik and Pc-Crash, A Simulation Program for Vehicle Accidents, MEA Forensic, Richmond, BC, Canada, 2016.

[57] W. E. Cliff and D. T. Montgomery, "Validation of PC-crash - a momentum-based accident reconstruction program," $S A E$ International, 1996.

[58] A. Moser and H. Steffan, "Automatic optimization of preimpact parameters using post impact trajectories and rest positions," SAE Transactions, pp. 897-906, 1998. 
[59] H. Steffan and A. Moser, The Collision and Trajectory Models of PC-CRASH, SAE Technical Paper, Rosemont illinois, 1996.

[60] D. S. Dima and D. Covaciu, "Vehicles frontal impact analysis using computer simulation and crash test," International Journal of Automotive Technology, vol. 20, no. 4, pp. 655-661, 2019.

[61] O. Prentkovskis, E. Sokolovskij, and V. Bartulis, "Investigating traffic accidents: a collision of two motor vehicles," Transport, vol. 25, no. 2, pp. 105-115, 2010.

[62] N. A. Rose and N. Carter, An Analytical Review and Extension of Two Decades of Research Related to PC-Crash Simulation Software, p. 523, SAE Technical Paper, Rosemont illinois, 2018.

[63] R. He and D. Zhang, Research on AEB Collision Avoidance Strategy Based on Characteristics of Driver-Vehicle-Road, SAE Technical Paper, Rosemont illinois, 2020.

[64] S. Khaleghian, A. Emami, and S. Taheri, "A technical survey on tire-road friction estimation," Friction, vol. 5, no. 2, pp. 123-146, 2017.

[65] C. Grover et al., "Automated emergency brake systems: technical requirements, costs and benefits," Automated emergency brake systems: Technical Requirements, Costs and Benefits, vol. 1, no. 1, pp. 1-109, 2013.

[66] D. Vangi, "Energy loss in vehicle to vehicle oblique impact," International Journal of Impact Engineering, vol. 36, no. 3, pp. 512-521, 2009.

[67] D. Vangi, F. Begani, M.-S. Gulino, and F. Spitzhüttl, "A vehicle model for crash stage simulation," IFAC-PapersOnLine, vol. 51, no. 2, pp. 837-842, 2018.

[68] J. Fox, Applied Regression Analysis and Generalized Linear Models, Sage Publications, McMaster University, Canada, 2015.

[69] T. R Core, R: A Language and Environment for Statistical Computing, SCRIP, Vienna, Austria, 2013.

[70] M. B. Kursa and W. R. Rudnicki, "Feature selection with the Boruta package," Journal of Statistical Software, vol. 36, no. 11, pp. 1-13, 2010.

[71] J. L. Speiser, M. E. Miller, J. Tooze, and E. Ip, “A comparison of random forest variable selection methods for classification prediction modeling," Expert Systems with Applications, vol. 134, pp. 93-101, 2019.

[72] D. P. Jenkins, N. A. Stanton, G. H. Walker, and M. S. Young, "A new approach to designing lateral collision warning systems," International Journal of Vehicle Design, vol. 45, no. 3, pp. 379-396, 2007.

[73] J. Chun, S. H. Han, G. Park, J. Seo, I. lee, and S. Choi, "Evaluation of vibrotactile feedback for forward collision warning on the steering wheel and seatbelt," International Journal of Industrial Ergonomics, vol. 42, no. 5, pp. 443-448, 2012.

[74] I. Han, B. Luan, and F. Hsieh, "Development of Autonomous Emergency Braking control system based on road friction," in Proceedings of the IEEE International Conference on Automation Science and Engineering (CASE), August 2014.

[75] G. Kim, H. Mun, and B. Kim, "Performance of AEB system on a slope using an extended kalman filter," International Journal of Software Engineering and Knowledge Engineering, vol. 29, no. 07, pp. 955-969, 2019. 